\title{
Probing cellular microenvironments and tissue remodeling by atomic force microscopy
}

\author{
Thomas Ludwig • Robert Kirmse • Kate Poole • \\ Ulrich S. Schwarz
}

Received: 30 September 2007 /Revised: 6 November 2007 / Accepted: 9 November 2007 /Published online: 6 December 2007

(C) Springer-Verlag 2007

\begin{abstract}
The function of cells is strongly determined by the properties of their extracellular microenvironment. Biophysical parameters like environmental stiffness and fiber orientation in the surrounding matrix are important determinants of cell adhesion and migration. Processes like tissue maintenance, wound repair, cancer cell invasion, and morphogenesis depend critically on the ability of cells to actively sense and remodel their surroundings. Pericellular proteolytic activity and adaptation of migration tactics to the environment are strategies to achieve this aim. Little is known about the distinct regulatory mechanisms that are involved in these processes. The system's critical biophysical and biochemical determinants are well accessible by atomic force microscopy (AFM), a unique tool for
\end{abstract}

\footnotetext{
T. Ludwig $(\bowtie) \cdot$ R. Kirmse

Group Microenvironment of Tumor Cell Invasion,

German Cancer Research Center,

BIOQUANT-Zentrum; BQ 0009 NWG Ludwig,

Im Neuenheimer Feld 267,

69120 Heidelberg, Germany

e-mail: t.ludwig@dkfz.de

K. Poole

Department of Neuroscience,

Max-Delbrück Center for Molecular Medicine,

Robert-Rössle-Strasse 10,

13125 Berlin-Buch, Germany

K. Poole

JPK Instruments AG,

Bouchestrasse 12,

12435 Berlin, Germany

U. S. Schwarz

Heidelberg University, BIOQUANT-Zentrum; BQ 0013 BIOMS Schwarz,

Im Neuenheimer Feld 267,

69120 Heidelberg, Germany
}

functional, nanoscale probing and morphometric, highresolution imaging of processes in live cells. This review highlights common principles of tissue remodeling and focuses on application examples of different AFM techniques, for example elasticity mapping, the combination of AFM and fluorescence microscopy, the morphometric imaging of proteolytic activity, and force spectroscopy applications of single molecules or individual cells. To achieve a more complete understanding of the processes underlying the interaction of cells with their environments, the combination of AFM force spectroscopy experiments will be essential.

Keywords Metastasis $\cdot$ Force spectroscopy $\cdot$ Force mapping $\cdot$ Mechanosensing $\cdot$ Matrix metalloproteinase . MMP · Stem cells $\cdot$ Integrin $\cdot$ ADAM $\cdot$ Nanoindentation · Cancer

\section{Introduction}

The complex interaction of cells with their microenvironment regulates the loss, acquisition, and maintenance of specific cellular functions in physiological and pathological conditions. The microenvironment of a cell consists of other cells of the same or different type, extracellular matrix components, fluids (for example extracellular fluid, urine), and the various molecular factors derived from these. The feedback loops of a cell and its surrounding is an indispensable element in cell homeostasis and the control of processes that require a remodeling of existing structures or the generation of new ones, for instance during morphogenesis. It is increasingly recognized that the micromechanics of the environment determine cell fate and function as much as soluble molecular factors do [22, $31,38,69,72,78,165]$. Here, atomic force microscopy 
(AFM) has proven to be a versatile tool, which enables essential questions to be addressed in this context, including the mapping of mechanical properties of cells and their microenvironments or the imaging of matrix remodeling through cell traction and pericellular proteolytic activity.

\section{Physical stimuli regulate cell biology}

Although many cell types respond to physical changes in their microenvironment as acutely as they do to chemical stimuli, the regulatory effects of these factors have been less extensively explored. The same mechanical factors can affect different cell types in fundamentally different ways [51, 172]. Substrate flexibility and geometry have been identified to drive morphogenesis, cell motility, polarity, proliferation, survival, and death $[4,22,74,99,102,117$, $154,155,174]$.

Microenvironments can be as diverse as calcified bone or elastic epidermal basement membranes. The field of rigidity sensing has been opened up with a pioneering study that used systematic variation of substrate stiffness. It demonstrated that cells show very different morphologies and adhesion structures on soft substrates compared to cells on rigid glass or plastic dishes, which are usually used for cell culture [117]. Many other cellular processes have been shown to depend on substrate stiffness [37, 84, 172]. Stem cell sustenance and differentiation is governed for example by specific microenvironments, the so-called stem cell niche $[47,167]$. The lineage specification of naive stem cells by soluble ligands is a well-established concept [49]. In contrast, it has only recently been recognized that the microenvironment's elasticity directs stem cell lineage commitment of naive mesenchymal stem cells (MSCs) [40]. In this study, the compliance of biologically inert polyacrylamide gels was tuned to mimic tissue-like conditions in vitro. In MSCs, bone-like rigid matrices gave rise to an osteoblast-like phenotype, and soft matrices, which mimicked brain-like conditions, proved neurogenic. Intermediate substrate stiffness induced a myogenic lineage. Soluble induction factors tended to be even less selective than matrix stiffness-driven stem cell programming.

The geometry of a stimulus can be in addition at least as important as its total amount. Studies with micropatterned adhesive substrates demonstrated that cellular response is determined by the spatial distribution of adhesive ligands, including the orientation of the cell division axis, or a cell's decision to proliferate or enter apoptosis [22, 45, 79, 153].

\section{Mechanosensing}

How do cells sense and relate to stiffness and geometry of their environment (Fig. 1)? In general, mechanotransduction can be based on many different physical aspects, and the exact details have to be investigated for specific systems. For example, although stretch-activated ion channels are the main molecular mechanism underlying our mechanotransductory senses of touch and hearing, they seem to play a minor role in rigidity sensing on soft substrates $[13,53,134$, 141]. Most evidence suggests that mechanotransduction based on rigidity sensing is localized to integrin-based sites of adhesion (focal adhesions) [10, 50]. Focal adhesions have a dual function. Firstly, they provide the structural support required to maintain adhesion to the substrate, in particular the structural continuity between the actin cytoskeleton and the extracellular matrix. Secondly, they are strong signaling centers that activate many important signaling cascades, including the ones regulated by the small GTPases from the Rho family [18]. A recent survey of the components recruited to focal adhesions (integrin adhesome) has revealed that at least 90 core components reside physically within the adhesion sites and at least 66 peripheral components

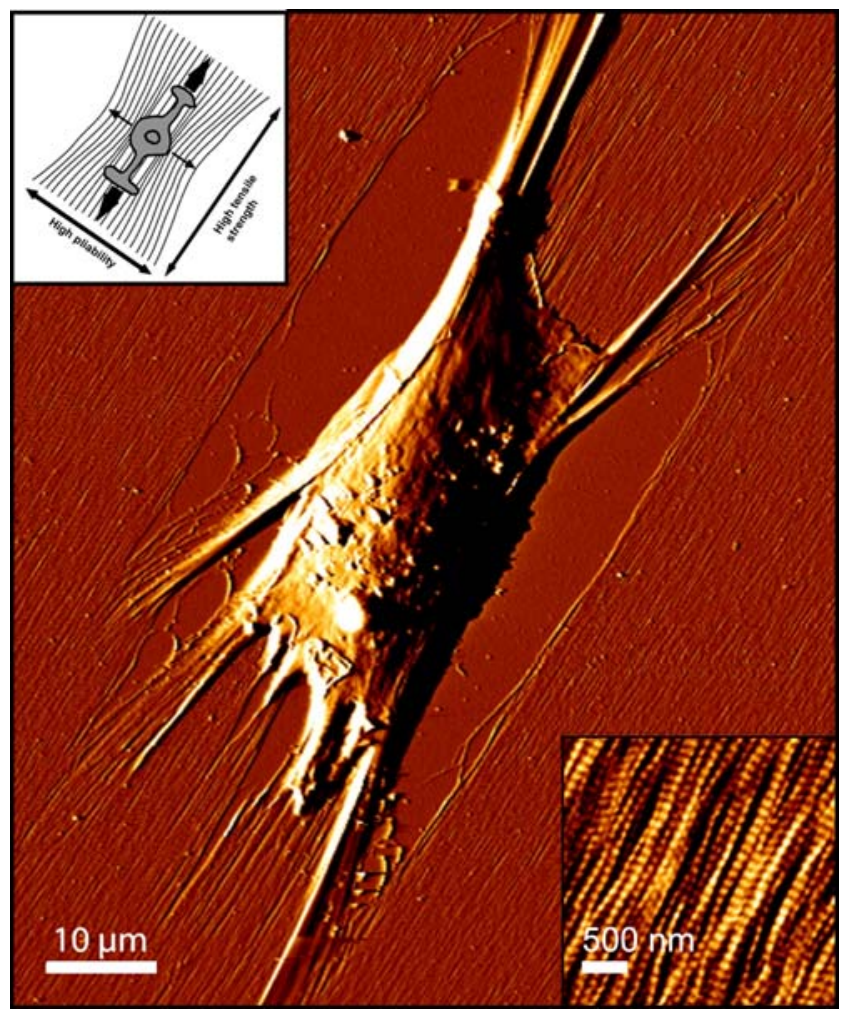

Fig. 1 Anisotropic matrix rigidity determines cell polarization. Cells, whether stationary or migrating, exert forces against their substrates as they anchor to, and pull on, their surroundings. By doing so, cells actively probe and sense the elasticity of their environment. Here, human osteoblast-like cells (SAOS-2), which stably express the $\alpha_{2}$ integrin subunit, were seeded on a nanoscopic matrix of parallel collagen I fibers (magnification, lower right corner) and imaged by AFM [45]. The high tensile strength of D-periodic collagen along the fibril direction enables strong cellular traction, whereas the high pliability of the matrix in the perpendicular orientation has the opposite effect (schematic model, upper left corner) [45] 
modulate their activity [173]. The core components can be classified into different functional groups, including transmembrane proteins (like the integrins), adaptor proteins (like talin and vinculin), cytoskeletal proteins (like actin and actinin), and different kinds of kinases, phosphatases, and Gproteins (like RhoA and Rac1). This survey demonstrated the abundance of biochemical switches in focal adhesions and that many interactions occur in assemblies of more than two proteins. Figure 2 summarizes the minimal set of components required to ensure the structural integrity of focal adhesions. Extracellular matrix proteins, for example collagen fibers, bind to transmembrane receptors of the integrin family that are connected to the actin cytoskeleton through adaptor proteins like the talin dimer.

Focal adhesions appear to be the main decision-making centers in regard to physical properties of the environment. In the stem cell studies, elasticity-directed lineage specification and sensing of matrix stiffness by the stem cells depended on myosin II contractility transmitted to the outside through focal adhesions [40]. Previous studies had already indicated that cell shape and cytoskeletal tension regulate cell lineage commitment of MSCs via RhoA signaling [95]. However, the transduction of forces into cellular signaling pathways is still poorly understood.

During cell spreading and migration, focal adhesions have been observed to be highly variable in shape and composition. This led to a classification where one distinguishes between focal complexes and focal contacts. Focal complexes are small contacts of less than $1 \mu \mathrm{m}$ that are based on integrinclustering close to the leading edge. If initial clustering is stabilized by the interplay between extracellular matrix

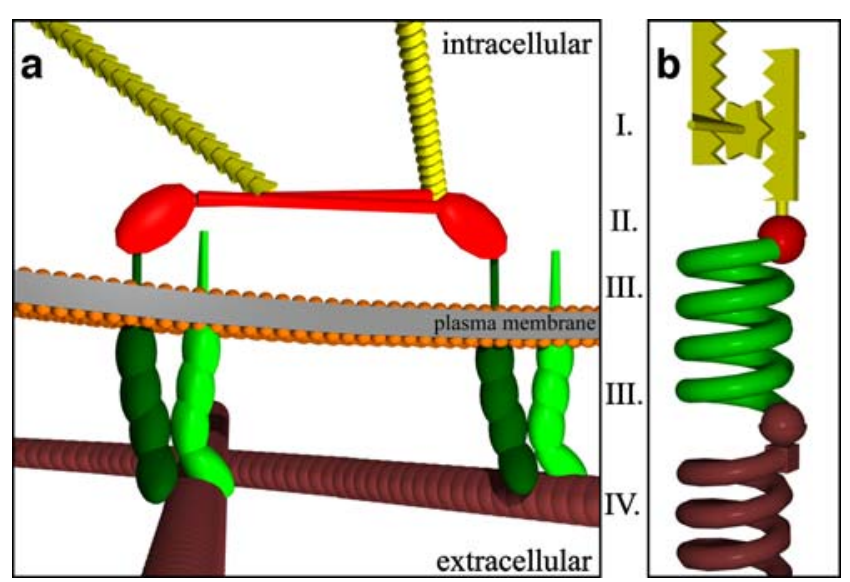

Fig. 2 Focal adhesions link intracellular actin cytoskeleton and the extracellular matrix. a Transmembrane receptors from the integrinfamily (III.) bind extracellular matrix proteins like collagen $(I V$.) with extracellular headpieces. Their cytoplasmic tails bind adaptor proteins such as the talin dimer $(I I$.$) , which in turn binds actin (I$.$) . b Schematic$ presentation of the mechanical situation at focal adhesions: The actomyosin system generates force that is transmitted through the cytoplasmic plaque to the extracellular matrix. The force is stored in the system at different positions and can lead to rupture events both outside and inside the adhesion properties and intracellular processes, focal complexes can mature into focal contacts, with a two- or threefold increased integrin packing density [6]. The buildup of force appears to be critical in this maturation switch. Several studies demonstrated the local growth of focal adhesions upon external force application (for example, [166]). The maturation of focal complexes into focal contacts can be considered to act as a checkpoint for crucial cellular decisions, like proliferation and migration, which require mature adhesion. Mature adhesion also leads to matrix remodeling and altered tissue mechanics, thus generating a feedback loop between the cell and its microenvironment (Fig. 3).

As the maturation of focal adhesions is such a crucial process in cellular decision making, their dissociation must also to be tightly regulated. Recent evidence suggests that dissociation of focal adhesions is mainly achieved by very precise targeting of microtubules into focal adhesions [50]. In cell migration, the use of the microtubule systems allows cells to coordinate the dissociation of focal adhesions in a global way, thus integrating the cues provided by local maturation processes at single focal adhesions.

The challenge - imaging and biomechanical probing

The fragile, local balance of physical and biochemical parameters within and outside single cells determines in a

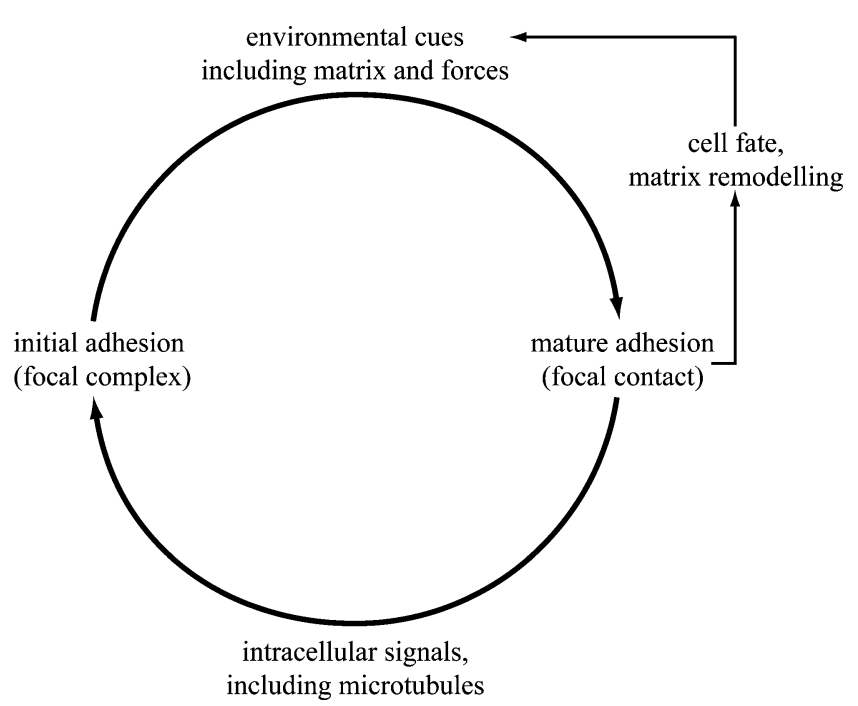

Fig. 3 Decision making in tissue cells depends on maturation of cellmatrix adhesions. Cell-matrix adhesions physically connect the cell to its environment and are strong signaling centers. Initial adhesions (focal complexes) mature into stable adhesions (focal contacts) only if the appropriate cues are present in the environment, including biochemical and mechanical properties of the extracellular matrix. The successful establishment of focal contacts determines many important cellular processes, including cell fate and matrix remodeling, which in turn determines maturation of adhesions. In this way, a feedback loop is closed, which is modulated by external signals. Focal contacts are dissociated in a globally coordinated process that involves microtubules being targeted into the sites of adhesion 
broader context the function of tissues, organs, and organisms. The mutual dependency of these parameters, e.g., rapid alterations in matrix properties as a result of proteolysis and tractile forces, requires a continuous adjustment and optimization on the subcellular level. The biological basis of and the challenges arising from such molecular and biophysical coherencies of cells and their microenvironments will be discussed in the context of current topics in tissue remodeling: the regulation of cellular microecology, the mechanical properties of cellular microenvironments, and cell adhesion and migration. Because different sample properties can lead in principle to similar response curves measured by the AFM, a theoretical understanding is crucial to assess the probed parameters (inverse problem of AFM). In this article, we discuss this challenge for the deconvolution of mechanical and adhesive events, rate dependent effects, elastic vs viscous responses, the mechanical signatures of the cytoskeleton vs the plasma membrane, protein assembly, and bond rupture in cell adhesion clusters.

\section{Atomic force microscopy}

The AFM evolved from the Nobel prize-winning scanning tunneling microscope (STM) [11]. The STM itself was the first instrument to generate real-space images of surfaces with atomic resolution $[7,12]$.

Although different in design, the essential part of each AFM is an imaging stylus that is composed of a cantilever with a sharp tip at its end (Fig. 4). The stylus is either moved line-wise across the sample by piezo-electric elements ( $x$ - and $y$-directions), or as in several AFMs, the stylus remains stationary, and the sample is moved [125]. In both designs, a laser beam is focused at the cantilever's back and reflected onto a split photodiode. There are two main modes of operation [126]. The first mode is commonly referred to as the static mode, as it records the static deflection of the cantilever. Weak repulsive or attractive forces between the sample surface and the tip result in the deflection of the laser. To maintain a constant force during scanning, the cantilever is moved vertically $(z-$ direction) by a piezo-electric element in response to the features of the sample (Figs. 4 and 5). The second mode is usually termed the resonance mode, as the cantilever is oscillated via a feedback loop at its resonance frequency. Each mode offers a number of variations, optimal for a distinct spectrum of applications. For example, operation in resonance mode enables noncontact, intermittent contact, phase imaging, and force modulation mode scanning.

Several features distinguish AFM from other highresolution imaging techniques such as electron microscopy. Native biological samples, for example live cells or tissue
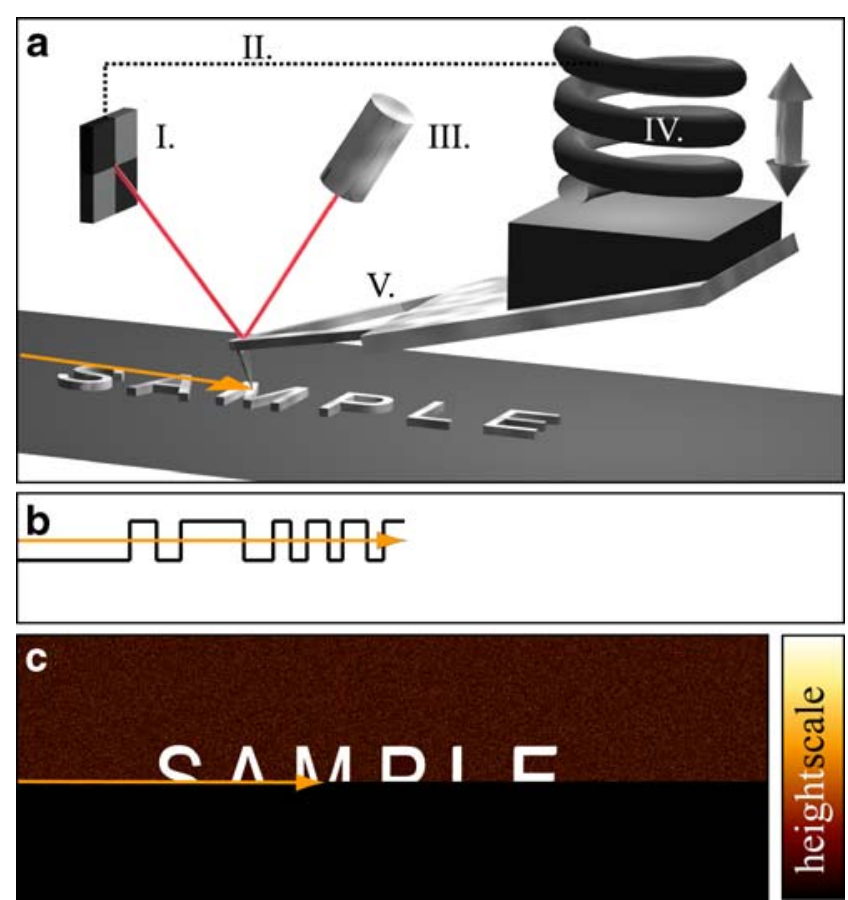

Fig. 4 Atomic force microscopy setup example (contact mode). a AFM utilizes the deflection of a thin silicon nitride spring $(V)$ with a fine probe at its end to reconstruct a topographical map of the sample surface. A laser beam (III) is focused at the end of the triangular spring (cantilever). Any tip movement causes a deflection of the spring that is registered by a photo detector $(I)$. A feedback loop (II) couples the photo detector to a piezo element $(I V)$ at the other end of the silicon spring. The corresponding height is calculated from the physical constants of the piezo crystal and the voltage that must be applied to it to bring the laser beam back into the center of the photo detector. $\mathbf{b}$ The AFM tip is moved line-wise (arrow) across the sample to collect $x, y$, and $z$ data $\mathbf{c}$ to reconstruct a topographical map of the sample surface
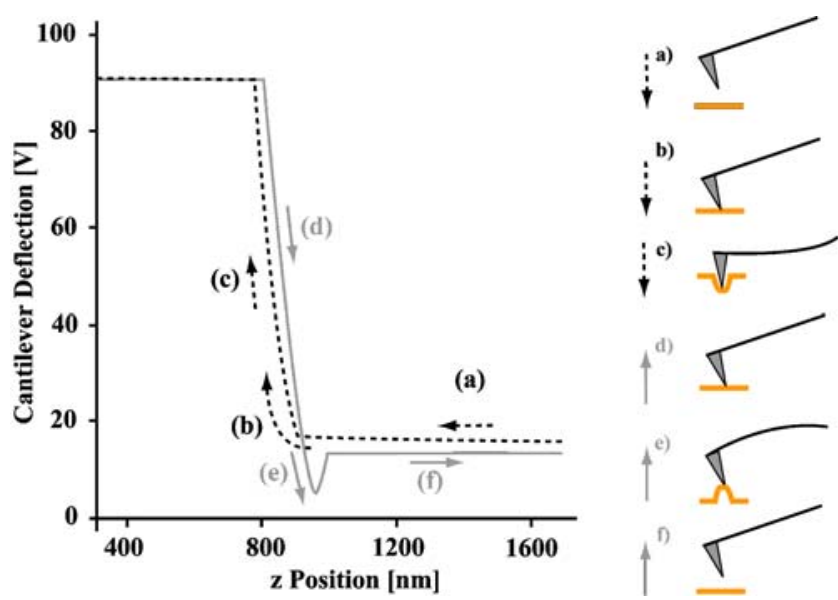

Fig. $5 \mathrm{AFM}$ force plot. For a force curve, the deflection of the cantilever is measured as the AFM tip approaches ( $a$ to $c$ ) and retracts ( $e$ to $f$ ) from the sample surface. Typically, the deflection is plotted against the vertical position of the piezo (z-position). a The cantilever starts from a point where it is not in contact with the surface. $\mathbf{b}$ After the tip has made contact, $\mathbf{c}$ the sample can be loaded with a controlled force by further approach of the tip. This results in an indentation in soft samples. d The cantilever is retracted after the given force is reached. e Adhesion of the tip because of interaction with the sample can cause bending of the cantilever until $\mathbf{f}$ the applied force is sufficient to separate the tip from the surface ("snap-off point") 
sections, can be investigated by AFM under physiological conditions. This means foremost at $37^{\circ} \mathrm{C}$ in buffered media. AFM is in addition a mechano-optical device that acquires primarily morphometric data. Morphometric implies that data points define $x$-, $y$-, and $z$-coordinates in space. As such, topographic real-space images are built. Because any color in the spectrum can be assigned to a specific height (z-dimension), the coloration of these topographic images is virtual.

\section{Force spectroscopy}

Given the mechanical nature of AFM, it can be used for more than imaging purposes. AFM can quantify forces in the range of a single antibody-antigen interaction and is used to study the physical properties of organic and inorganic samples at a nanoscale. The cantilever can be moved in a controlled fashion in the $z$-direction, to probe samples at specific regions. Significant biophysical information can be obtained from this vertical movement, while the cantilever is in contact with the sample (Figs. 5, 7, 8, and 9).

According to its mode of use, the cantilever of the AFM can be considered a spring, where the deflection of the cantilever depends primarily on the elastic properties of the cantilever and the surface. On stiff samples, the deflection of the cantilever is directly proportional to the vertical travel of the piezo once the AFM tip has touched the surface ("contact point"). On soft samples, this will result in the indentation of the sample (Figs. 5c and 7b). The indentation can be calculated as the difference between vertical piezo movement and the deflection of the cantilever after the contact point. At the simplest level, the cantilever deflection curve represents a qualitative measure for the elasticity of the sample. The shallowness of the slope of the cantilever deflection increases with the compliance of the surface. This approach offers two principle modes of measurement, either the force that is necessary to yield a given extent of sample indentation (i.e., $200 \mathrm{~nm}$ ) or, inversely, the indentation resulting from a given loading force (i.e., $100 \mathrm{pN}$ ) can be quantified.

Upon retraction, probe-sample interactions can bend the cantilever toward the surface. As these bonds break, the cantilever will snap up, and the specific force required to break the bonds can be calculated. There are many permutations of this type of experiment, from the unfolding of single proteins to the use of individual cantilever-bound cells (Figs. 6 and 14) [9, 36, 64, 111, 127].

In practice, the force exerted by (or on) the cantilever can be calculated using Hooke's law $F=k d$, where $k$ is the spring constant and $d$ the deflection of the cantilever. The deflection can be determined by performing a forcedistance curve on a stiff sample. In this curve, the deflection of the cantilever is directly proportional to the vertical movement of the piezo. As such, the split photo diode registers the deflection of the cantilever as a voltage difference, which can be converted into nanometers.

The quantification of the cantilever's spring constant is less straightforward. For idealized cantilevers with a rectangular cross-section, the formula $k=E t^{3} w /\left(4 L^{3}\right)$ could be applied, where $E$ is Young's modulus, $t$ and $w$ are the thickness and the width of the cantilever, and $L$ is the length from the tip apex to the cantilever base [2]. For two-legged triangular cantilevers, the equation can be adjusted, i.e., by calculating with twice the width. The spring constants of commercially available cantilevers range from $0.01 \mathrm{~N} / \mathrm{m}$ for soft cantilevers to $50 \mathrm{~N} / \mathrm{m}$ for stiff ones. Because structural defects and variations in thickness and cantilever composition are frequent, this nominal spring constant represents only an approximation that cannot be used for absolute force measurements. Accordingly, a number of more accurate methods have evolved. Briefly, these can be grouped in three major categories, of which the latter two are the more common ones: (1) use of the cantilever resonance, (2) static loading methods, and (3) utilization of thermal noise $[19,24,52,54,71,146,157]$. The spring constant of a cantilever can be derived from a change in its resonance frequency after the addition of a known mass [24]. For the static loading method, a reference cantilever with a known spring constant $\left(k_{0}\right)$ is mounted upside down on the sample stage and used to acquire force-distance curves with the cantilever in question. The spring constant of the unknown cantilever $\left(k_{1}\right)$ can be calculated as $k_{1}=k_{0}$ $[C(D / N)-1]$, where $C$ is the conversion factor determined for the voltage-nanometer conversion (see above), $D$ is the vertical piezo displacement, and $N$ is the deflection (in $\mathrm{V}$ ) [52]. The precision of this method depends on the accuracy of the $k_{0}$ value and on the difference between $k_{0}$ and $k_{1}$. Although complex in its theoretical background, thermal noise detection is probably the most elegant method for the determination of a cantilever's spring constant. In practice, the spring constant can be deduced from the mean square of the vertical deflection of the cantilever caused by the Brownian motion of its media [19]. One advantage of this method is the possibility to conveniently quantify spring constants online immediately before and after experiments.

Measuring forces in cellular systems

There are two fundamentally different ways by which cells generate force, namely by polymerization (e.g., of microtubules or actin filaments) and by molecular motor activity (mainly myosin, kinesin, and dynein). Force generation can be compressive or tensile, which corresponds on the cellular level to cell expansion and retraction. One of the main structural proteins in animal cells is actin that can be used for both purposes. Monomeric actin is globular (G- 
actin) and readily polymerizes into polarized filaments (Factin). As addition of a new monomer is energetically favorable, this process can be used to expand the cell. In principle, depolymerization can be used to create a retraction process, like the retraction of bacterial pili [90]. In mammalian cells, however, the main mechanism for retraction is myosin molecular motor activity on actin filaments. Myosin molecular motors are nonprocessive motors that rapidly dissociate from the filament after performing the power stroke. Hence, they have to work in sufficiently large ensembles. At any given time, fractions of motors are in a state before and after the power stroke, sharing the functions of force generation and keeping the tension in the bundle, respectively. The main structures of this kind are muscles and cellular stress fibers. In the cellular context, force generation by actin polymerization and force generation by actomyosin contractility are often coupled. For example, during cell spreading and migration, the envelope is pushed out by polymerization, but at the same time, myosin molecular motors in the lamella behind the lamellipodium help to pull the actin network away from the membrane. Moreover, actomyosin contractility is essential to retract the trailing edge to allow forward propulsion of the cell body.

Force generation can be investigated in a quantitative manner with the AFM on the molecular and cellular level (Fig. 6). By adsorbing the bacterial actin nucleation factor ActA onto a cantilever, the formation of an actin network between the cantilever and a nearby surface can be initiated (Fig. 6a) [116]. The network grows initially with a velocity of $72 \mathrm{~nm} / \mathrm{min}$ until it stalls at a cantilever pressure of $1 \mathrm{kPa}$. When this pressure was decreased by cantilever retraction, the actin network continued to grow. This demonstrates how a physical effect (force) regulates the biological function (extension of the actin network). The AFM can also be used to investigate how cells extend against an external obstacle (Fig. 6b). To study this, a micron-sized polystyrene bead was glued to a cantilever and positioned in front of a locomoting keratocyte, a popular in vitro model of a quickly moving cell [17]. In agreement with the aforementioned experiment, the cell was found to exert pushing pressure against the cantilever of the order of $1 \mathrm{kPa}$. Moreover, it was found that the migrating cell shows strong deformation when encountering the obstacle and in fact was able to squeeze through a gap between cantilever and surface as small as $500 \mathrm{~nm}$. Experiments that employed a similar approach suggested a density of approximately 100 polymerizing actin filaments per micrometer of the leading edge [119]. The obtained force vs velocity plots indicated a complex, multiphase process of force generation in migrating cells.

Other pivotal AFM studies clarified the mechanical dynamics at active and stable edges of migrating cells and enabled direct measurement of lamellipodial protrusive forces [119, 129]. Previous AFM-based reports included the observation of actin filament dynamics in living glial cells and the morphometry of processes at the lamellipodium of migrating epithelial cells [60, 107, 139]. Force mapping of the leading and trailing edges of 3T3 fibroblasts demonstrated a Young's modulus of "nonactive" cell edges of approximately $12 \mathrm{kPa}$, whereas the leading edge had an approximately $60-70 \%$ lower stiffness [129]. Because stiffness corresponds here to the cortical tension of the cells, these measurements are in accordance with a model of actin polymerization-driven leading edge propulsion.

\section{Force mapping}

Force maps are 2D arrays of parameters derived from single-force plots that can be obtained by the probing of surfaces in a raster-like fashion (Figs. 6, 7, 8, and 9). Considering the dimensions of an AFM tip, force mapping can be used to characterize the properties of sample areas with a high spatial resolution. A frequent application is the mapping of the elastic modulus. The elastic modulus, also known as Young's modulus, describes the stiffness of a

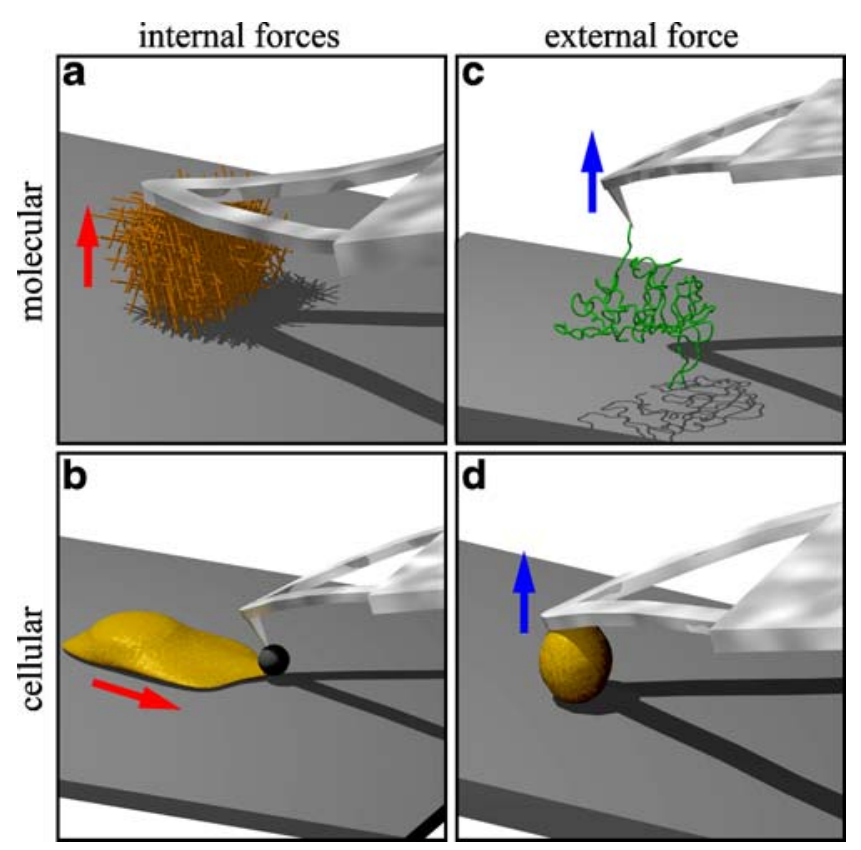

Fig. 6 Cellular and molecular probing by AFM. a Force generation by polymerizing actin gels can be measured between the AFM cantilever coated with an actin polymerization factor and a nearby surface. b In the cellular context, actin polymerization leads to lamellipodium extension of a spreading or locomoting cell against external load, which can be controlled with the AFM. c The mechanical response of single biomolecules under a linear ramp of force can be probed with the AFM by retracting the cantilever with different speeds. d When adhering cells are pulled off a substrate with AFM, one probes both cell mechanics and the physical stability of the adhesion bonds. Different retraction speeds lead to different results because bond rupture is a thermally activated process 

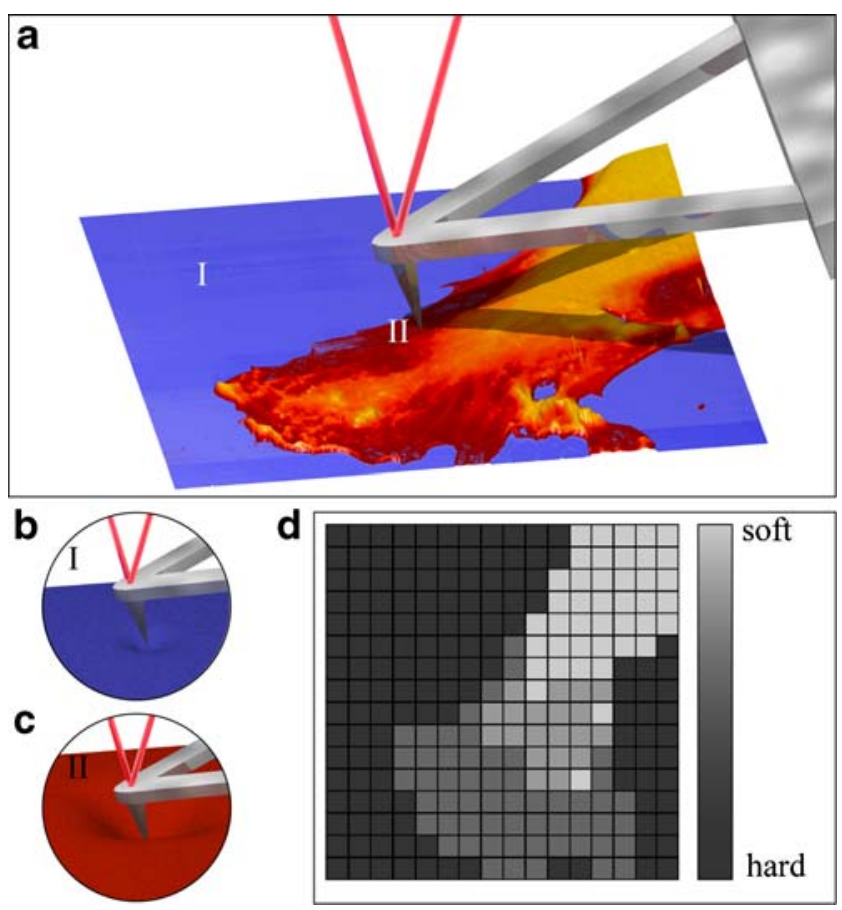

Fig. 7 Elasticity mapping. a The AFM tip can be used for direct probing of small sample areas, i.e., of the leading edge of a cell. $\mathbf{b}$ If the AFM tip is moved directly toward a stiff surface (i.e., the glass of a coverslip), deflection of the cantilever is proportional to the piezodriven vertical displacement. c In soft samples, such as a cell's leading edge, indentation of the surface results in a discrepancy of deflection signal and piezo travel. d Probing surface properties in a raster-like fashion results in a "force map." The force map displays the distribution of the mechanical properties of the scanned area and can be directly correlated with previously acquired morphometric images of the same region

material. It is derived from the stress to strain ratio. Stress is defined as the force normalized by the cross-sectional area of the material. Strain is the ratio of the change in length to initial length. Typical parameters for unfixed cells are in the range of 1 to $10 \mathrm{kPa}$ and up to $100 \mathrm{kPa}$ for fixed ones (for example, $[65,128,138])$. As a comparison, the Young's modulus for rubber is about $2 \mathrm{MPa}$ and for glass about $1 \mathrm{GPa}$ [138].

For quantitative elasticity mapping of samples, a number of obstacles and nonlinearities must be considered. The contact point is usually hard to determine in soft samples, as the force plot becomes shallower with decreasing Young's moduli [44, 122, 138]. Furthermore, common AFM tips have a conical or pyramidal geometry. The contact area increases accordingly with the indentation depth. These problems have been solved by the application of theoretical models, which meet the practical requirements of AFM force mapping [33, 122, 138, 149]. In short, Hertz [63] found in 1882 an analytical solution that describes the elastic deformation of two spheres touching under load. The model has been extended to a more suitable solution for AFM tips to the geometry of a cylindrical cone indenting an elastic half space by Sneddon [60]. This socalled Hertz model relates loading force and resulting indentation.

Combination of optical and atomic force microscopy

Because AFM is a high-resolution surface technique, the application of AFM with light microscopy adds valuable accessory information (i.e., on intracellular antigen distribution). This combination is frequently needful for the effective investigation of cellular processes. In addition, optical microscopy enables precise positioning of the AFM tip, for example to perform force spectroscopy on a region of interest (Figs. 8 and 9).

With transparent sample supports, such as coverglass, AFM imaging can be combined with optical microscopy techniques like phase contrast, differential interference contrast, epifluorescence, laser scanning confocal microscopy, and total internal reflection fluorescence (for example, [77, 94]). However, the true integration of AFM and optical images is challenging. Optical microscopy is based on the use of lenses with intrinsic aberrations that distort the final image. In contrast, AFM images are generated with very precise linearized piezo-electric elements, with a precision of $3 \AA$ in the $x$ - and $y$-dimensions. This means that the AFM image can be considered a "real-space" image. As such, in most cases, the AFM image and the light microscopy image do not accurately overlay, with shear or stretch in the optical image being a common problem. One technical solution is the calibration of the optical image by the movement of the AFM tip. Briefly, the cantilever is steered to a defined set of coordinates. At each point, an optical image is acquired, and subsequently, the tip location within the optical image is determined. A transform function is then calculated and applied to the optical image (Figs. 8 and 9) [87].

\section{Challenges in combining experiment and theory}

The AFM allows one to measure force vs extension traces, both on the molecular and cellular level (Fig. 6). These data need to be interpreted in quantitative terms [43, 144]. Early work for single molecules yielded conflicting results, which were reconciled with the notion that force spectroscopy data for single molecules has to be interpreted in the framework of stochastic dynamics [42]. In brief, if bond rupture is modeled as the transgression of a transition state barrier, the force at which a bond breaks under a ramp of force is not a static quantity. It depends on the rate of loading: The faster the bond is loaded, the higher is the force at which it breaks because thermal fluctuations have less time to assist the rupture. In quantitative detail, it has been shown 

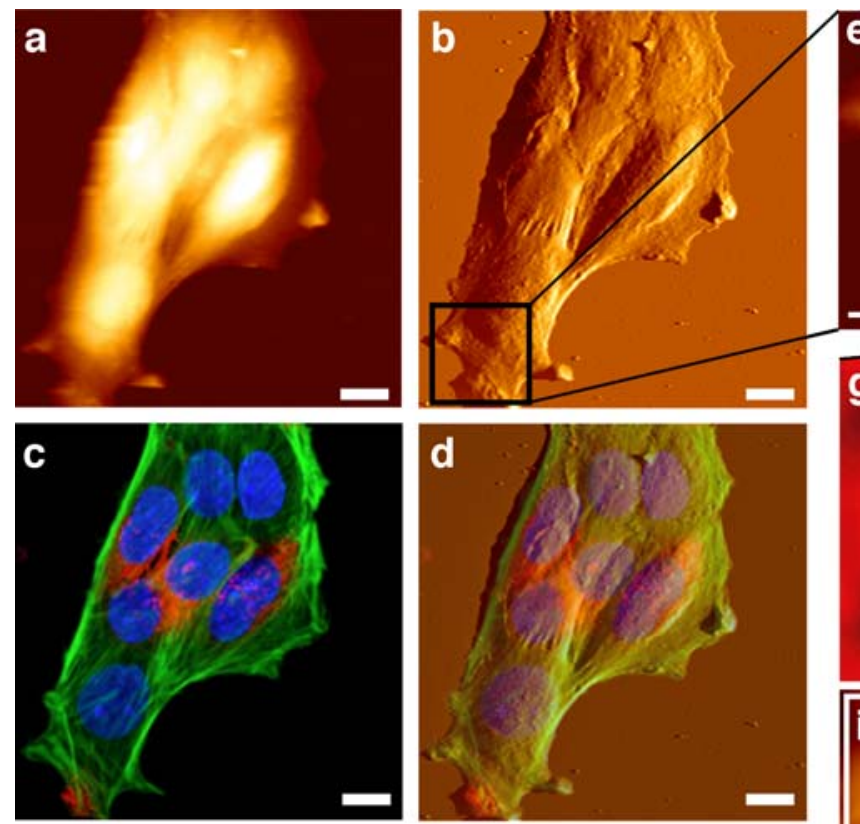

scale bar for:

$\mathrm{a}, \mathrm{e}$

i
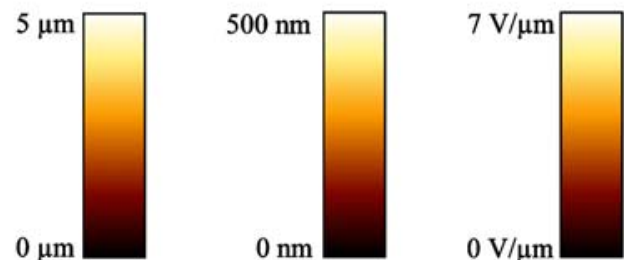

Fig. 8 Combined AFM and confocal imaging of mouse embryonic fibroblasts. Embryonic fibroblasts were grown on coverslips and stained for actin (green; FITC phalloidin), clathrin (red; rabbit anti clathrin heavy chain/TRITC goat anti rabbit), and dsDNA (blue; DAPI). a-d A contact mode AFM image and a calibrated, cofocal microscopic image of the same sample were overlaid to combine the AFM's 3D morphometric data with fluorescence information. a Height topography, b cantilever deflection, c laser-scanning confocal

that bond strength increases with the logarithm of the loading rate. This prediction has been confirmed in many experiments, for example for biotin-avidin interactions [98].

Dynamic force spectroscopy has also been applied to a number of adhesion systems, in particular to the integrin, selectin, and cadherin systems. Using molecular modeling, it was found that the extracellular matrix protein fibronectin exhibits stable intermediates under force, suggesting that force might be an important regulator also of the extracellular matrix [76]. Recently, it was found for the P-selectin system that force impedes rather than facilitates bond rupture [91]. P-Selectin is expressed by activated endothelial cells to mediate the interaction with PSGL-1 present on the surface of leukocytes. In principle, bonds can be weakened ("slip bonds") or even strengthened ("catch bonds") by the application of external force. It is interesting to note that P-selectin complexes with PSGL-1 displayed a

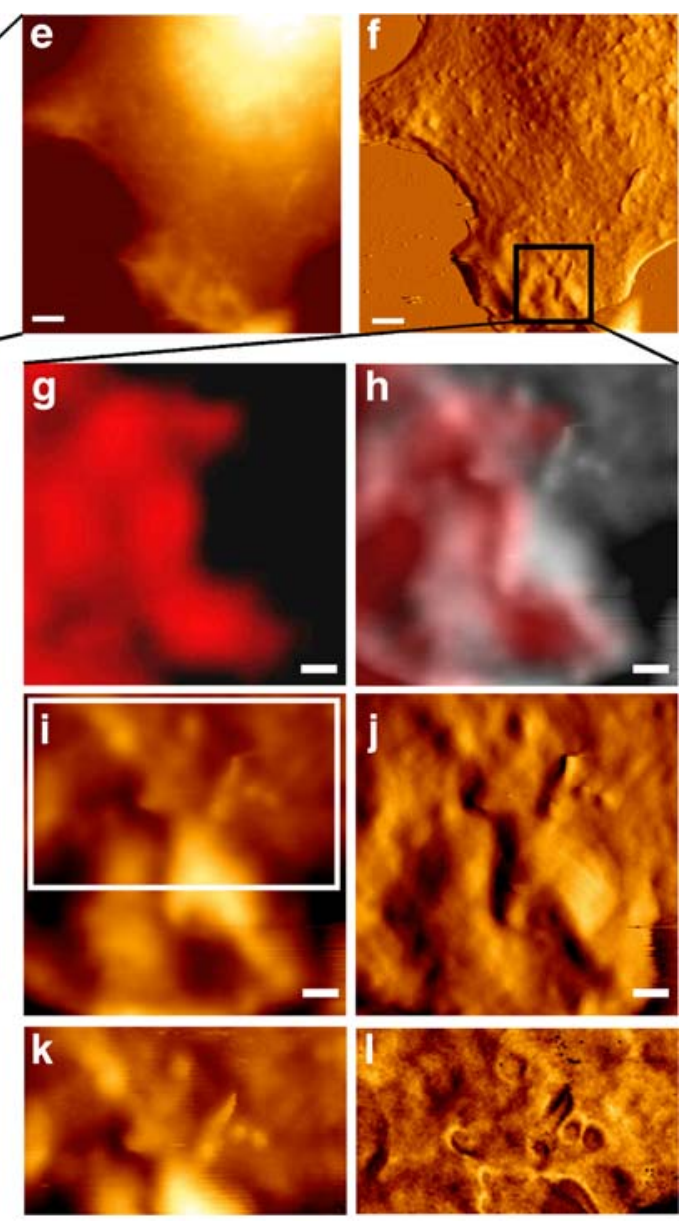

image, and d overlay of AFM height and confocal image. Higherresolution images were acquired by zooming into the marked regions. $\mathbf{e}, \mathbf{i}$ Height and $\mathbf{f}$, $\mathbf{j}$ cantilever deflection images. $\mathbf{g}$ Confocal and h overlay of confocal and AFM image. A high-resolution force map was generated with an applied force of $200 \mathrm{pN}$. k Topography represents the height of the piezo at which the set point $(200 \mathrm{pN})$ was reached, and $\mathbf{I}$ the slope of the indentation curve represents a basic measure for stiffness. [87]

biphasic response with a transition from a catch-bond- to a slip-bond-like state. After an initial increase upon force application, bond stability decreased with higher forces. This provides a potential mechanism for the regulation of cell adhesion during mechanical stress. Nonetheless, a complete molecular and quantitative understanding of this catch-bonding behavior has not been achieved yet.

It is important to note that biomolecular bonds never function alone in a physiological context. Particularly, cell adhesion is based on the clustering of adhesion molecules into larger assemblies. In adhesion clusters, the bonds are arranged along the plasma membrane in a parallel way, which leads to strong cooperativity in bond rupture: As one bond ruptures, force is distributed over the remaining bonds (Fig. 10). Using theoretical models for the stochastic dynamics of adhesion clusters under force, it has been shown that this cooperativity leads to rupture cascades and 

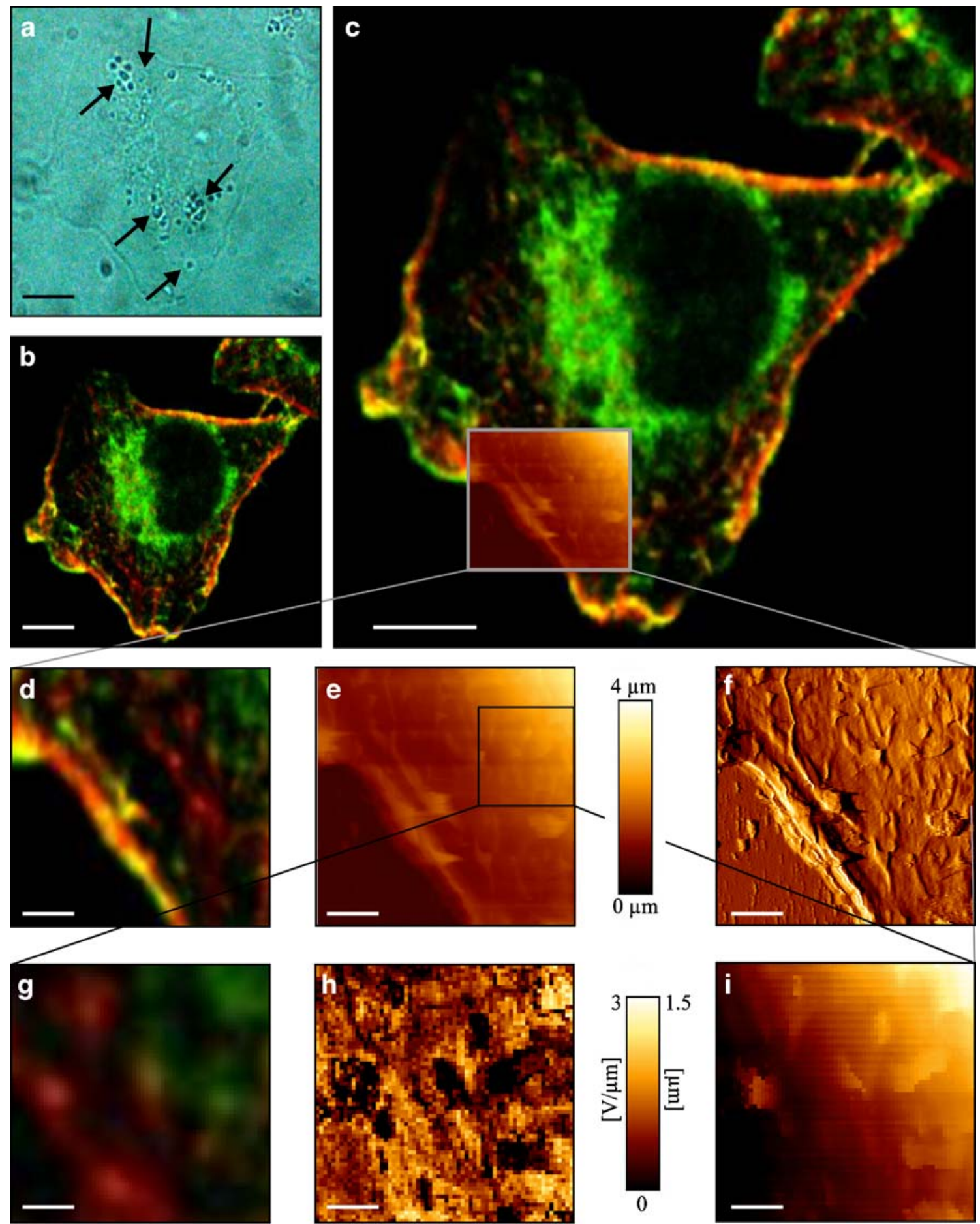

Fig. 9 Combined AFM and confocal imaging of actin and b1-integrin in human melanoma cells. Melanoma cells (A375, ATCC) were cultured on glass coverslips and stained for filamentous actin (green; TRITC-phalloidi) and b1-integrin (red; ms anti $\beta 1$-integrin/ FITC goat anti-mouse). All optical images were calibrated by a transform function obtained from AFM-tip real-space coordinates. a The bright-field image displays pigment-containing melanosomes. b The confocal image displays colocalization of the actin and $\beta 1$ integrin signal, but $\beta 1$ integrin is not exclusively localized at actin-based structures at the surface [118]. c Location of the AFM and fluorescence images is displayed in $\mathbf{d}$, e, and f. e AFM height image obtained in contact mode and $\mathbf{f}$ trace direction error signal. $\mathbf{h}$ The slope of the cantilever deflection during indentation is displayed. It indicates the variable stiffness of different regions of the cell surface. The force map was generated by taking force-distance curves on each point of the map using the same cantilever as used for imaging. The applied force at each point was $250 \mathrm{pN}$. i Topography derived from the piezo height at the setpoint of $250 \mathrm{pN}$. The surface of the cell is decorated with flexible ridges that can be seen moving in the scan direction. Comparison with $\mathbf{d}$, the fluorescence image shows that most of these structures correspond to the actin signal 

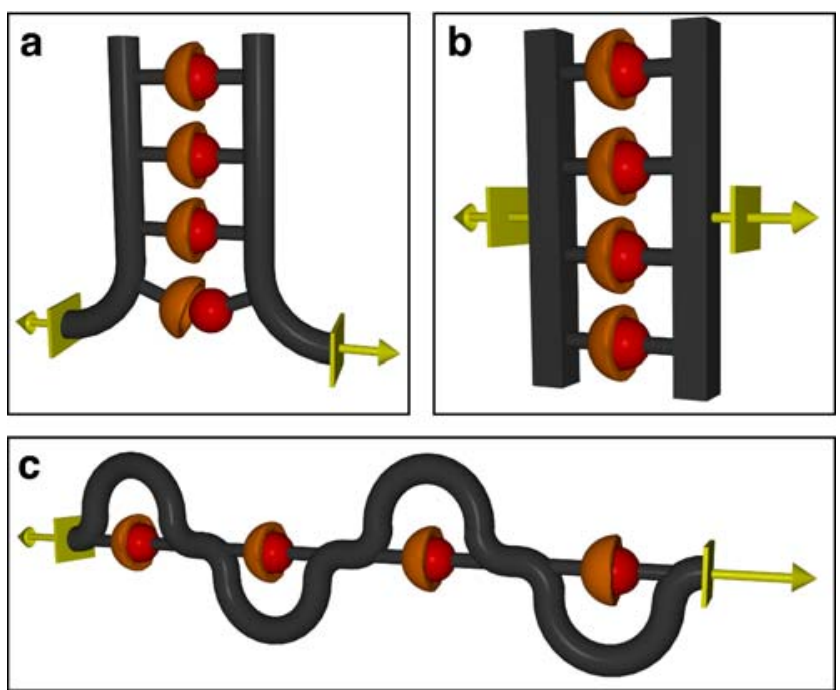

Fig. 10 Architecture dependent rupture of bond clusters. a Rupturing of DNA-like assemblies is a peeling process in which one bond ruptures after another, thus only the lead bond is under loading and there is little cooperativity between the different bonds. b Adhesion clusters like integrin-mediated cell-matrix adhesions are arranged in a parallel architecture along the plasma membrane. Loading through the actin cytoskeleton leads to strong cooperativity. If one bond breaks, the mechanical load is redistributed. c Loading of the muscle protein titin leads to a different type of cooperativity: If one domain unfolds (conceptually equivalent to bond rupture), the contour length suddenly increases, and force on the remaining folds decreases

a stability threshold under force [41]. Future modeling efforts have to investigate in more detail the interplay between mechanics and rupture in complex geometries (Fig 11).

\section{Cellular microecology and proteolytic activity}

Despite the methodological progress in defining the biological effects of a specific biochemical activity, the direct quantification of this activity itself is often challenging. For example, direct quantification of proteolytic activity has proven significantly difficult. In 1962, Gross and Lapiere [56] published an article based on the observation that cut-off tadpole tails, which were placed on collagen-coated culture dishes, degraded fibrillar collagen. The discovery of collagenolytic activity in tadpole fins during metamorphosis uncovered the connection of tissue remodeling and proteolytic activity and led in later years to the identification of collagenase I, the founding member of a protease family commonly known as matrix metalloproteinases (MMPs) [15]. Since their discovery, the interest in MMPs has been constantly growing as these enzymes have been found to be upregulated in innumerable pathologies $[21,89,161,175]$. For instance, because of common biological requirements, the function of proteases constitutes a final common pathway in the spreading of cancers, independent from their diversity in many other respects $[34,57,147]$. Regulated proteolytic activity is a prerequisite for tumor cells to balance (1) attachment to and detachment from the extracellular matrix (ECM), (2) the ECM's biomechanical properties, and (3) the overall structure of their microenvironment. Accordingly, the connection of the metastatic potential of cancer cells and their ability to degrade basement membrane proteins was recognized early [83].

Otherwise, the knowledge regarding the physiological functions of MMPs is still relatively concise [115]. Regardless of the proven abundance of MMPs in developing tissues, the phenotypes of MMP knockout mice were surprisingly subtle $[1,27,67]$. It must be considered that MMPs have broadly overlapping substrate specificities [34, $96,145]$. The lack of dramatic phenotypes in mice deficient in one MMP demonstrates probably nature's preference to back up vital mechanisms instead of their nonessentialness. As a matter of fact, concurrent ablation of MT1-MMP (MMP-14) and MMP-2 has been demonstrated to be lethal in mice [112].

The function of MMPs goes beyond simple matrix degradation. MMP substrates include among others prominent chemokines (e.g., latent transforming growth factor $\beta$ [TGF- $\beta]$, pro-tumor necrosis factor $[\mathrm{TNF}] \alpha$ ) and their receptors (e.g., interleukin 2 [IL2] receptor $\alpha$ ), serin proteases

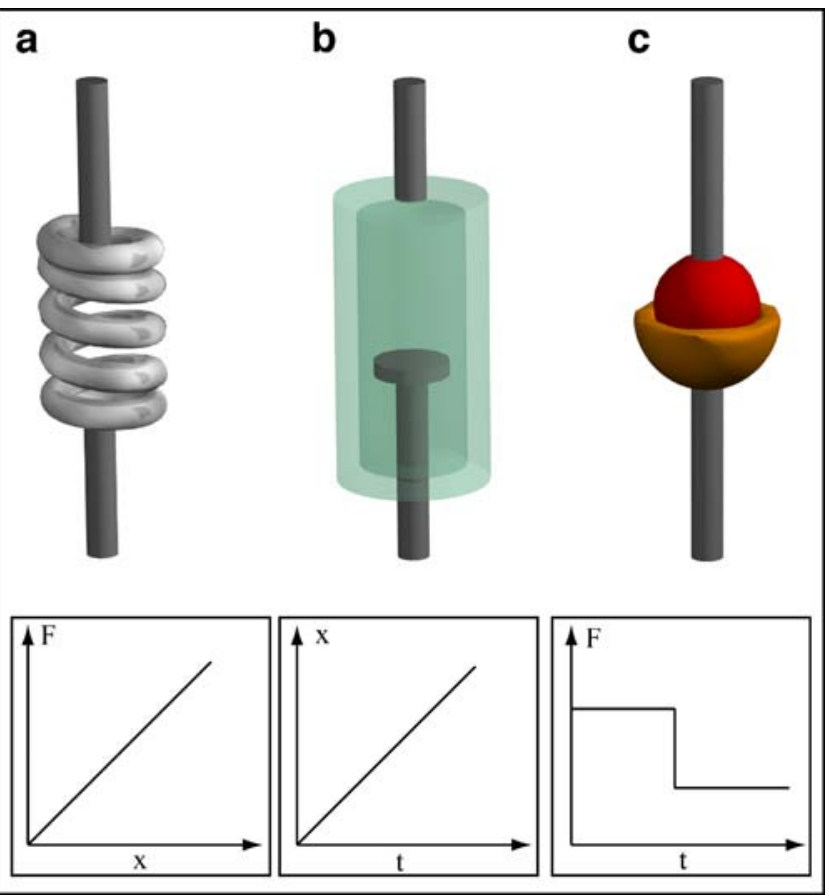

Fig. 11 Biological material under load shows different types of mechanical responses. a A perfect elastic material (depicted as a harmonic spring) shows a linear force-extension relation. The slope defines the spring constant and time is not relevant. b A viscous material (depicted as dashpot) flows and thus extension grows with time under constant force. The slope defines viscosity. c Bond failure leads to sudden relaxation and thus to jumps in the force curves. Because bond rupture is a thermally activated process, jump heights are rate dependent 
(plasminogen), their activators (urokinase-type plasminogen activator), and inhibitors (e.g., antithrombin III, $\alpha 1$-antichymotrypsin, $\alpha 2$-macroglobulin) [34, 145, 147]. The cleavage of matrix proteins can additionally unleash new biological properties that could not be observed in the intact molecules. The exposure of such cryptic sites within the matrix and the release of macromolecule fragments have been implicated in significant events governed by cell-ECM interactions. This includes cell migration, adhesion, and differentiation [100, $135,171]$.

\section{Challenges: imaging and quantification of local processes}

Despite the progress in defining the biological effects of single proteases, the precise quantification of proteolytic activity remains difficult. This methodological gap is pinpointed by the disastrous failure of synthetic MMP inhibitors in cancer therapy $[5,15,16,85,114]$. Although criticism regarding the general setting of these trials is reasonable, they questioned the actual knowledge regarding the regulation of proteolytic activity [26]. The quantification of proteolytic activity in vitro and even more in situ is hampered by two major obstacles: excessive posttranslational regulation and spatial restriction (Fig. 12b), both of which are major topics of ongoing research themselves [85, $88,89,136]$.

The proteolytic activation and inactivation of proteins can rapidly induce irreversible changes in a cell's microenvironment. Consequently, this activity is closely controlled on the transcriptional, translational, and post-translational level. Most methodological problems are related to the posttranslational regulation of proteases because of the discrepancy between concentration and activity [85]. The activity of proteases is post-translationally modified by their activation, inactivation, endogenous protease inhibitors, glycosylation, oligomerization, and protein trafficking [86]. Limited proteolysis of proteases themselves can also modify their distribution, substrate specificity, and inhibitor affinity. The proteolytic processing of many proteases varies depending on the prevalence of the activity of other proteases. For instance, cleavage of a sequence close to the transmembrane domain of MT-MMPs can generate soluble subspecies of these proteases [62, 73, 113, 158]. Although these shed proteases are catalytically active and may now act as soluble proteases, they have apparently lost most of their biological activity $[20,68]$. As a result, protease action must obviously occur in the immediate cellular surrounding to contribute to the regulation of the pericellular microenvironment [89]. Not surprisingly, mechanisms that confine and concentrate protease activity in the pericellular space have been found to be essential in tumor cell invasion [85, 88]. Among others, these mechanisms comprise the expression of membrane-anchored proteases and receptors for soluble ones by cancer cells $[85,86]$. Being responsible for both activation of other proteases and spatial restriction of proteolytic activity, MT1-MMP gave rise to the most severe phenotype of a single MMP deficiency observed in mice so far [66].

Morphometric quantification of pericellular proteolytic activity

A set of classic biochemical methods can be employed to investigate the expression of proteases and their inhibitors on the transcriptional and translational level. Other than that, it is not possible to deduce proteolytic activity from the mere concentration of a protease in a tissue section or extract. Thin fluorescence-labeled substrate coatings can be utilized to detect and assess local proteolytic activity in the microenvironment of cells under tissue culture conditions (Fig. 12) [89, 101]. However, this method has a limited resolution and is semiquantitative at most.

AFM overcomes the limitations of standard techniques as it enables nanoscale imaging and functional quantification of processes in the microenvironment of live cells (Fig. 12d). The investigation of cells on protein coatings (collagen IV and gelatin) by AFM detected a significant decrease in average height and volume of matrix protein coatings in the pericellular space of cancer cells (Fig. 12d) [77, 85-87]. The experiments proved a steep increase in proteolytic activity of several magnitudes toward the microenvironment of invasive cells. In addition to the morphometric evaluation of areas of 1 to $4 \mu^{2}$ of the protein coating, clusters and individual proteins of the matrix could be imaged. By treating them as sphere segments, their molecular volume and weight were assessed [61, 137]. The number of identifiable single proteins and protein clusters increased toward the periphery of cells, whereas their volume and molecular weight decreased. This constitutes the nanoscale morphological correlate of proteolytic matrix cleavage.

AFM had previously been used for real-time imaging of the proteolysis of individual collagen I molecules by collagenases [150]. Imaging of the cleavage of tropocollagen II by MMP-8 with single-molecule resolution by AFM revealed the existence of several MMP-8-binding sites on the tropocollagen molecules, although cleavage occurs only in one specific location [82].

Morphometric imaging by AFM has been applied to investigate the remodeling of other distinct cellular microenvironments. Mineralized bone for example poses a peculiar environment (Fig. 13c). Its remodeling requires the coordinated demineralization and degradation of its organic collagen I matrix by osteoclasts. Demineralization is achieved by the acidic conditions produced by vacuolartype H,K-ATPase, whereas proteolytic activity is required to cleave the fibrillar collagen. As a result, osteoclast 


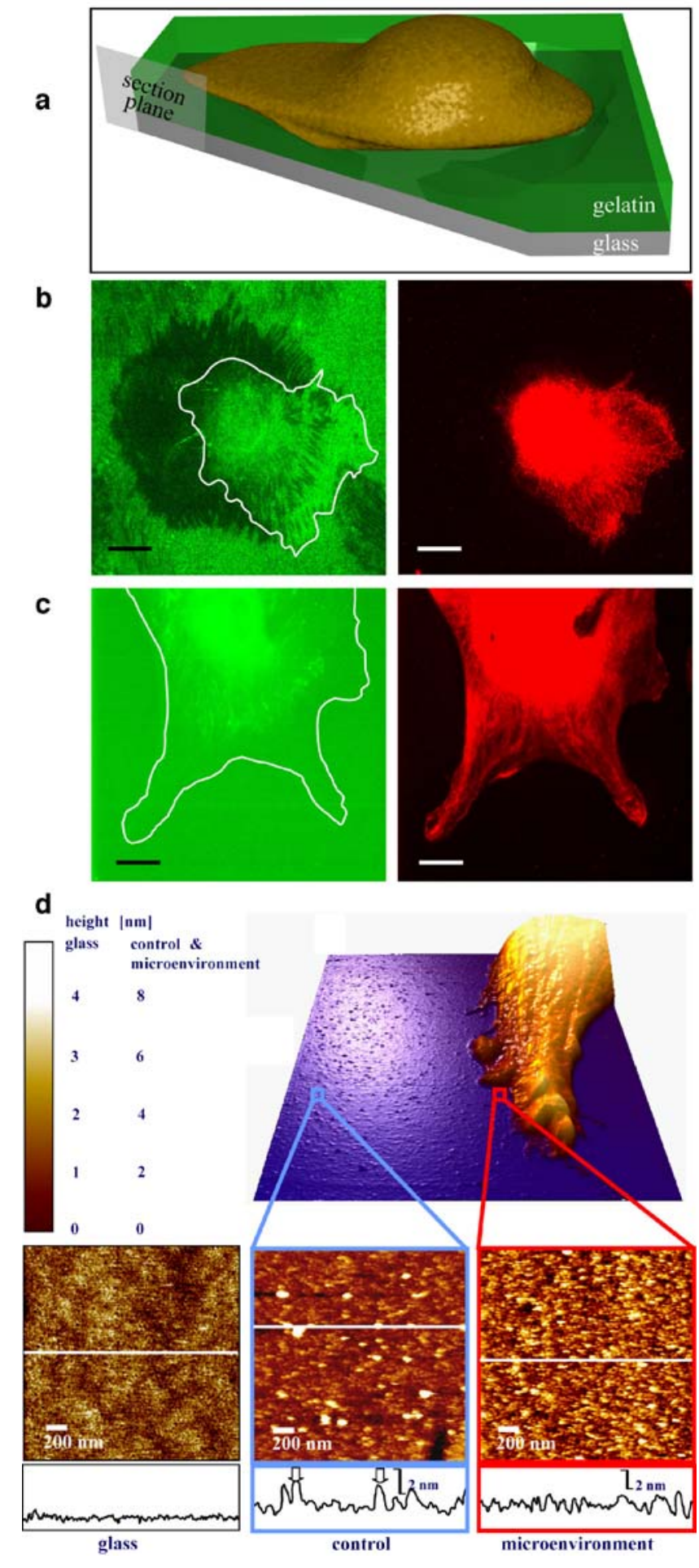

activity is marked by the formation of small cavities (Fig. 13b,c). AFM proved superior to electron microscopy for the direct morphometric investigation of the depth and morphology of these resorption pits $[30,58]$.
Fig. 12 Proteolytic microenvironment-fluorescence microscopy and AFM. a Schematic model of pericellular proteolytic cleavage by a cell on a matrix coating (gelatin). b Glioblastoma and $\mathbf{c}$ astrocytoma cells were seeded on a surface coated with fluorescence-labelled gelatin (left) and immuno-stained with anti MMP-2 (right). Substrate cleavage, occurring here only in microenvironment of invasive glioblastoma cells, is indicated by a local loss of fluorescence. d Melanoma cells, seeded on the same gelatin coated surface, were imaged by AFM in contact mode. By decreasing the scanned matrix area (see magnified areas), structural features of the substrate coating become apparent. Matrix areas in the pericellular microenvironment display an increase in particle number and a decrease in particle sizethe morphological correlate of proteolytic protein cleavage. As the AFM acquires primarily morphometric data, the average volume and height of scanned areas above a given threshold (defined by the lowest point in the coating) can be directly derived. In invasive cells, the morphometric AFM data proved quantitatively a steep decrease in proteolytic activity within several micrometers distance from the cell

Force spectroscopy applications-from single molecules to cells and their microenvironments

The nanomechanical cues derived from ECM proteins have been studied on the single-molecule level by force spectroscopy (Fig. 6c). Stretching of individual molecules of the extracellular matrix protein tenascin for example revealed that this molecule could be extended to several times its resting length [105]. The force-distance plot displayed a pronounced saw-tooth pattern, with each peak related to the unfolding of one of its domains. The modular building by individually folded domains is a common principle of protein structures. However, both properties, the extensibility and the force-elongation pattern, have been related to tenascin's fibronectin III (FNIII) domains. This behavior extends to other FNIII-containing molecules like fibronectin and could contribute for example to matrix elasticity and cause the maintenance of protein-ligand interactions over long distances [103, 104]. Similar force spectroscopy experiments have been performed on a number of proteins, for instance on the muscle protein titin and collagen I fibrils [55, 127].

However, despite the significant insights derived from single-molecule force spectroscopy, the micromechanical properties of a complex environment cannot be deduced from the sum of its constituents. While "bulk" tensile testing of tissues may be used to assess the properties of larger tissue sections, this method is inefficient to determine local parameters. These might be highly heterogeneous throughout the sample. Hence, direct mechanical probing and mapping by AFM of tissue sections, cells, and their microenvironments poses an important methodological extension. At a larger scale, AFM can be applied to study tissue sections like arteries or to dentin [39, 92]. For example, the arterial media layer is mainly populated by smooth muscle cells that appear to be highly susceptible to the mechanical input from their surrounding [37]. In this 
context, the microelastic modulus of the arterial media layer has been determined by AFM force spectroscopy to be in the range of 5-8 $\mathrm{kPa}$ [39]. Additionally, the matrix deposited by osteoblasts under tissue culture conditions had for example a stiffness of approximately $30 \mathrm{kPa}$ as measured by AFM [39].

Considering the impact of mechanical stimuli, the knowledge of the in vivo conditions is essential to reproduce these in vitro. Vice versa, AFM can be used to control the elasticity of synthetic, polymer-based substrates such as thin polyacrylamide gels for tissue culture applications [44, 75].

Given the coherency of cells and their microenvironments, AFM force spectroscopy and mapping have been extensively employed for the investigation of acute and long-term biomechanical responses of cells to physical and pharmacological stimuli. As such, AFM has been used to map the responses of osteoclasts to different substrates, the age-related stiffening of cardiomyocytes, and the effects of actin-disrupting drugs on fibroblast compliance or acute and long-term effects of aldosterone on endothelial cells $[33,81,106,108,109,130,140]$.

\section{Cell adhesion}

Cell-cell and cell-matrix adhesions are a prerequisite for the organization of cells into tissues and complex organisms. At the cellular level, adhesion controls cytoskeletal organization, gene expression, proliferation, migration, and survival [131]. The complex nature and methodological challenges of cell adhesion originate from the diversity and interdependency of the contributing biophysical and biochemical processes.

Physiological cell function depends on the correct context of stimuli from a specific surrounding. Most adherent cell types cease proliferation and become quiescent in the absence of appropriate matrix contacts $[8,25]$. Presentation of matrix in the wrong spatial orientation, e.g., exposure of the apical side of polarized renal epithelial cells to fibrillar collagen I, can even result in apoptosis ("disoriented cell death") [151]. Otherwise, the prolonged removal of cells from their physiological environment and disruption of cell adhesion induces usually "lonely cell death," as observed in epithelial and endothelial cells [46, 97]. Derived from the Greek word for homelessness, this special form of apoptosis has been termed anoikis [46]. This mechanism ensures that these types of cells do not survive in the absence of proper matrix interactions and renders them unable to survive, for example, in the bloodstream or to proliferate at inappropriate sites. In contrast, cancer cells are capable of evading anoikis after the detachment from their surroundings and are frequently able to divide in the absence of adhesion to a solid extracellular matrix [148].
Cell adhesion relies on the expression of distinct cell adhesion molecules (CAMs). The vast majority of CAMs belong to five principal families of integral membrane proteins: the immunoglobulin superfamily, cadherins, selectins, mucins, and integrins. CAMs stabilize tissue integrity, and many of these molecules have been identified to suppress cancer cell spreading, whereas loss or alteration in their functionality can be associated with an invasive phenotype $[14,110,159]$. For example, transfection of epithelial cancer cells with E-cadherin attenuated their invasiveness, whereas E-cadherin inhibition by antibodies or transfection of specific antisense RNA had an opposite effect [164].

However, even under physiological conditions, as in morphogenesis or wound repair, the detachment and increased motility of cells may become necessary. After the preliminary closure of a lesion by fibrin, vessel formation and re-epithelialization require the rapid migration of keratinocytes and the invasion of the fibrin matrix by endothelial cells $[23,48,93]$. Because adhesion factors "glue" cells to their environment and thus impede cell migration, deadhesion
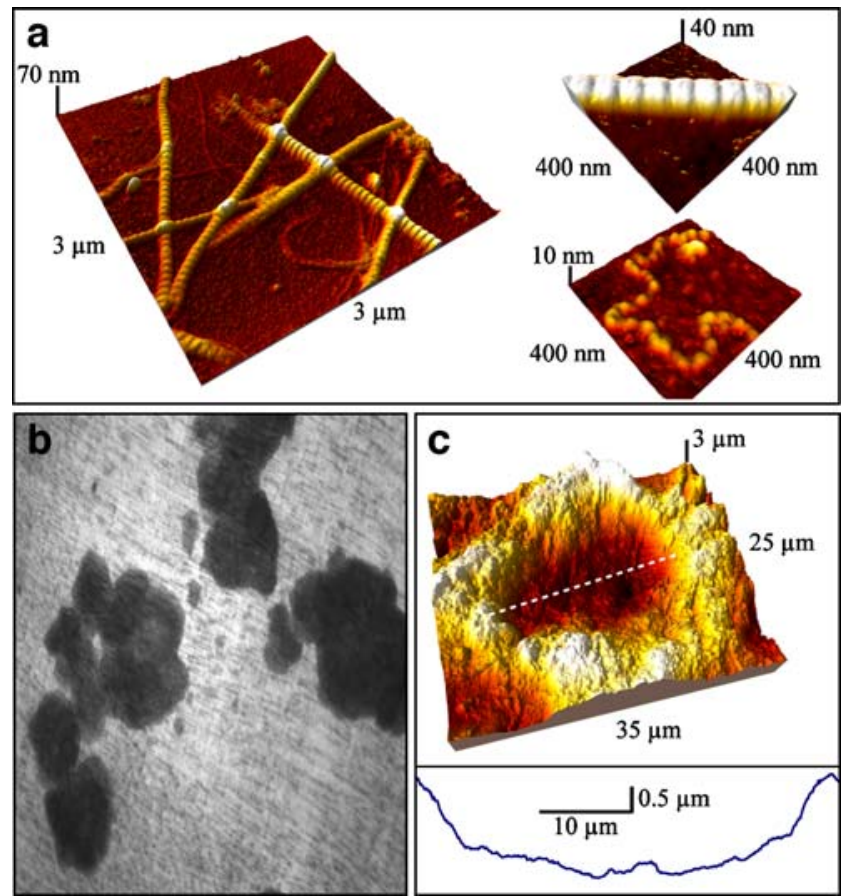

Fig. 13 Microenvironments: human epidermal basement membrane and osteoclastic pits. a Three dimensional reconstruction of AFM images from normal human skin preparations enriched in basement membranes. b Osteoclasts were prepared from tibia growth plates of 4- to 5-week-old mouse puppets, subcultured, and seeded on bovine dentin disks. The formation of characteristic resorption pits is a result of demineralization and proteolytic cleave the collagenous matrix by the osteoclasts. c Pit from a single osteoclast with cross-section 
factors elicit the opposite effect. Disintegrins constitute one such class of factors. Integrins recognize the tripeptide sequence RGD or related motifs, which are presented by many adhesion promoting matrix proteins as a key structural component of their receptor-binding domain (e.g., fibronectin, collagens, and fibrinogen) [132]. Disintegrins contain the RGD sequence and compete consequently with integrinECM interactions [123].

Proteases like MMPs constitute another significant class of detachment-regulating factors. Emanating from the diversity of their targets, the mechanisms by which they regulate cell adhesion and migration are no less diverse. Constituting a protein family that combines two of the major entities of adhesion-regulating factors, a disintegrin and metalloprotease (ADAM) proteins are predestined to regulate cell adhesion and signaling [123, 142]. ADAMs are multidomain proteins that commonly contain a disintegrin and metalloproteinase domain. ADAMs, also known as MDCs (metalloprotease, disintegrin, and cystein-rich domains), essentially combine the already extensive biological spectra given by their principal domains. While the disintegrin domain modulates integrin binding and signaling, the metalloproteinase domain can cleave ECM components and - probably even more importantly - cell surface proteins. ADAMs are currently emerging as the major mediators of ectodomain shedding (for example [80, 124]). Besides their relevance to inflammatory diseases and cancer, ADAMs are putative key regulators of morphogenesis (for example, [3, 70, 178]).

On the face of it, ADAMs can exert conflictive functions. ADAMs facilitate cell detachment via matrix cleavage or shedding of CAMs, but they can otherwise mediate cell-cell interactions by integrin binding. This implies once more that a protein's actual biological effect depends essentially on the complex subcellular context of its microenvironment.

Single-cell force spectroscopy by AFM-a "nano-forklift" for cells

Given the heterogeneous composition of cell surfaces, the dynamic probing of cell adhesion of single cells is challenging [143]. In principle, quantitative information on cell adhesion strength and mechanical properties can be obtained by the application of external forces. Several AFM-based techniques for the characterization of cell adhesion have evolved to utilize the AFM's unparalleled imaging and force-sensing capabilities. These methods range from the morphological evaluation of adhering cells to the controlled displacement of cells by the application of lateral forces with a modified AFM setup [133, 143]. Among these methods, AFM force spectroscopy of single cantilever-bound cells represents a unique experimental platform for the investigation of cell-cell and cell-matrix interactions (Figs. 6d, 14, and 15).

After binding individual cells to an AFM cantilever, these cells (1) can be brought into contact with other cells or protein coated surfaces, (2) establish contact for a given period of time, and (3) be separated by pulling them away from the surface (Fig. 14). The conditions that define the approach and withdrawal of these cells-applied force, contact time, and pulling speed - can be precisely controlled in such experiments by benefiting from the AFM's high-force sensitivity and spatial resolution [87]. The data collected in these experiments include information on repulsive forces before contact, cell deformability, maximum unbinding forces, individual unbinding events, and the total work required to remove a cell from the surface.

The AFM "nano-forklift" approach has been used to study cell adhesion in various systems $[9,120,121,152$, $156,169,170,177]$. It must be considered that cells may display different adhesion properties in a two-dimensional system compared to a three-dimensional matrix environment $[28,29]$. With this in mind, the validity of cell adhesion measurements with AFM depends strongly on the resemblance to physiological interactions. As such, AFM force spectroscopy experiments yielded the first quantitative data of the initial interaction forces of trophoblasts and maternal tissue. The implantation and hence the survival of blastocysts depend critically on their adhesion to the uterine epithelium. To resemble this situation, human trophoblasttype cells (JAR) grown on microbeads were mounted on cantilevers and brought into contact with epithelial uterine monolayers [156].

Force spectroscopy of single cells distinguishes itself clearly from tissue culture-based bulk assays that assess the average behavior of larger cell populations. Force spectroscopy can identify cell subpopulations and characterize the regulation of cell adhesion events online with singlemolecule resolution [152]. Analysis of discrete cell adhesion forces demonstrated a dynamic increase of adhesion organization over time [152]. In these experiments, cells stably expressing the $\alpha_{2} \beta_{1}$ integrin were allowed to adhere to collagen I for different periods of time. Individual cells displayed a rapid increase in total adhesion force after 1 min of surface contact, and the smallest discrete rupture events rose above that of single integrin bonds. It is interesting to note that both effects of $\alpha_{2} \beta_{1}$ integrinmediated cell adhesion were abolished by inhibition of actomyosin contractility [152].

The transmigration of leukocytes through endothelia (diapedesis) is a prerequisite for their access to sites of inflammation. The adhesion of leukocytes to the vascular endothelium is a key step in this process [162]. The proinflammatory cytokine TNF- $\alpha$ stimulates the surface expression of intercellular adhesion molecule (ICAM) 1 in 
endothelial cells and initiates the adhesion of leukocytes. This step is essential for the physiological response to pathogens but also for the pathogenesis of inflammatory diseases like arteriosclerosis. To study the interaction of endothelial cells with leukocytes, a quantitative approach is necessary. Again, single-cell force spectroscopy has been used in this context for the characterization of cell adhesion events $[35,169,170,176]$. A combination of AFM force
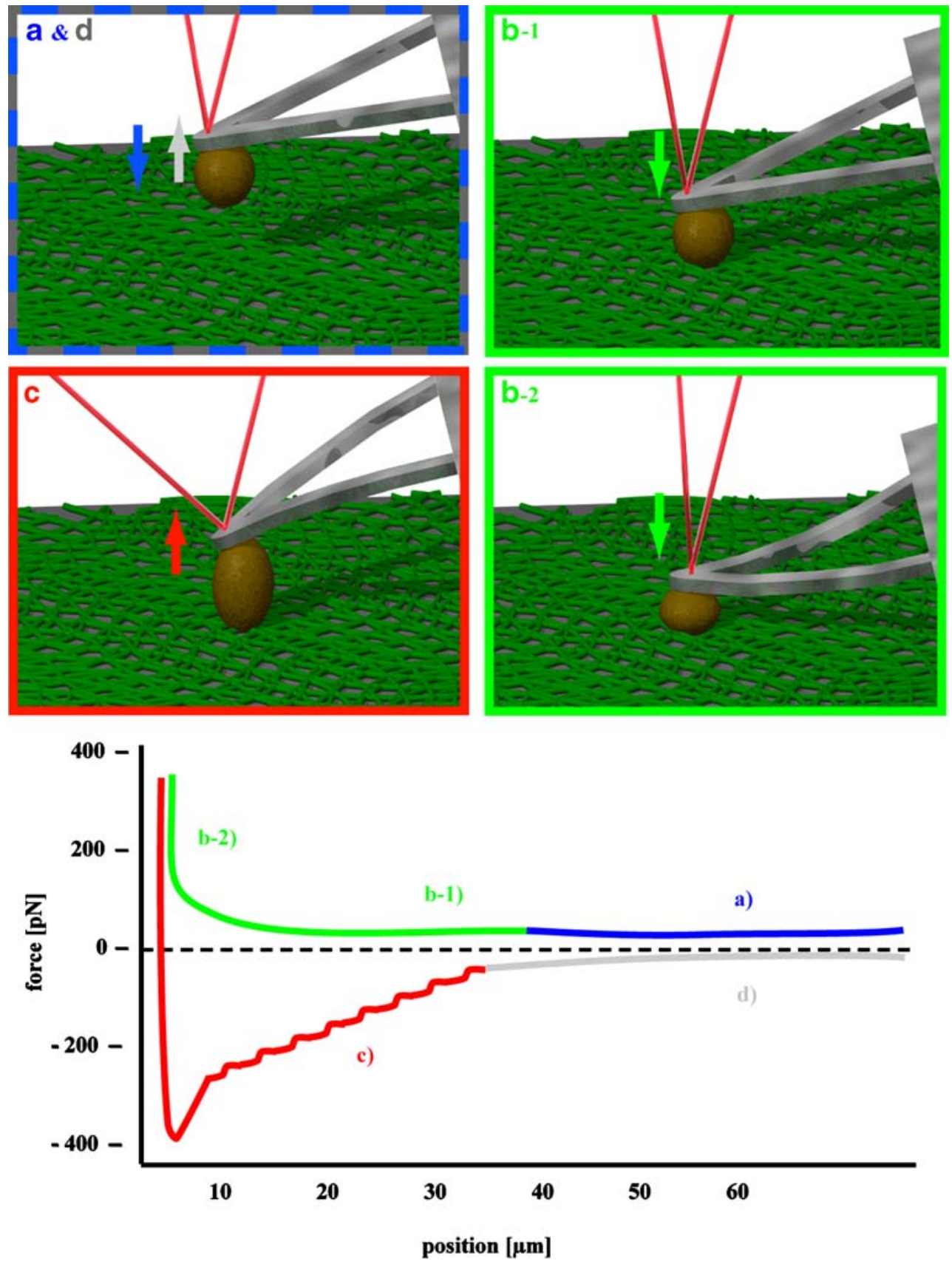

Fig. 14 Single-cell force spectroscopy. The position given by the piezo element ( $x$-axis) is plotted against cantilever deflection ( $y$-axis, representative of the applied force). a In the initial phase of the approach, the cantilever is not deflected. b-1 Once the cell touches the surface, the cantilever begins to deflect. The slope of the deflection is determined in part by the elasticity of the cantilever-bound cell. b-2 The movement of the piezo element stops for a given contact time when the desired deflection or force (the set point) is reached. c Soon as the piezo element moves in the opposite direction, the cantilever- bound cell starts to separate from the surface. Bonds between the cell and the surface pull the cantilever toward the surface. As these bonds break, the cantilever snaps up, corresponding to "jumps" in the forcedistance curve. The size of these jumps indicates the force required to break the interaction at the given retraction speed. d After all of the bonds between the cell and the surface are broken, the cantilever will no longer be deflected, and the piezo element will continue moving until a set distance is reached 

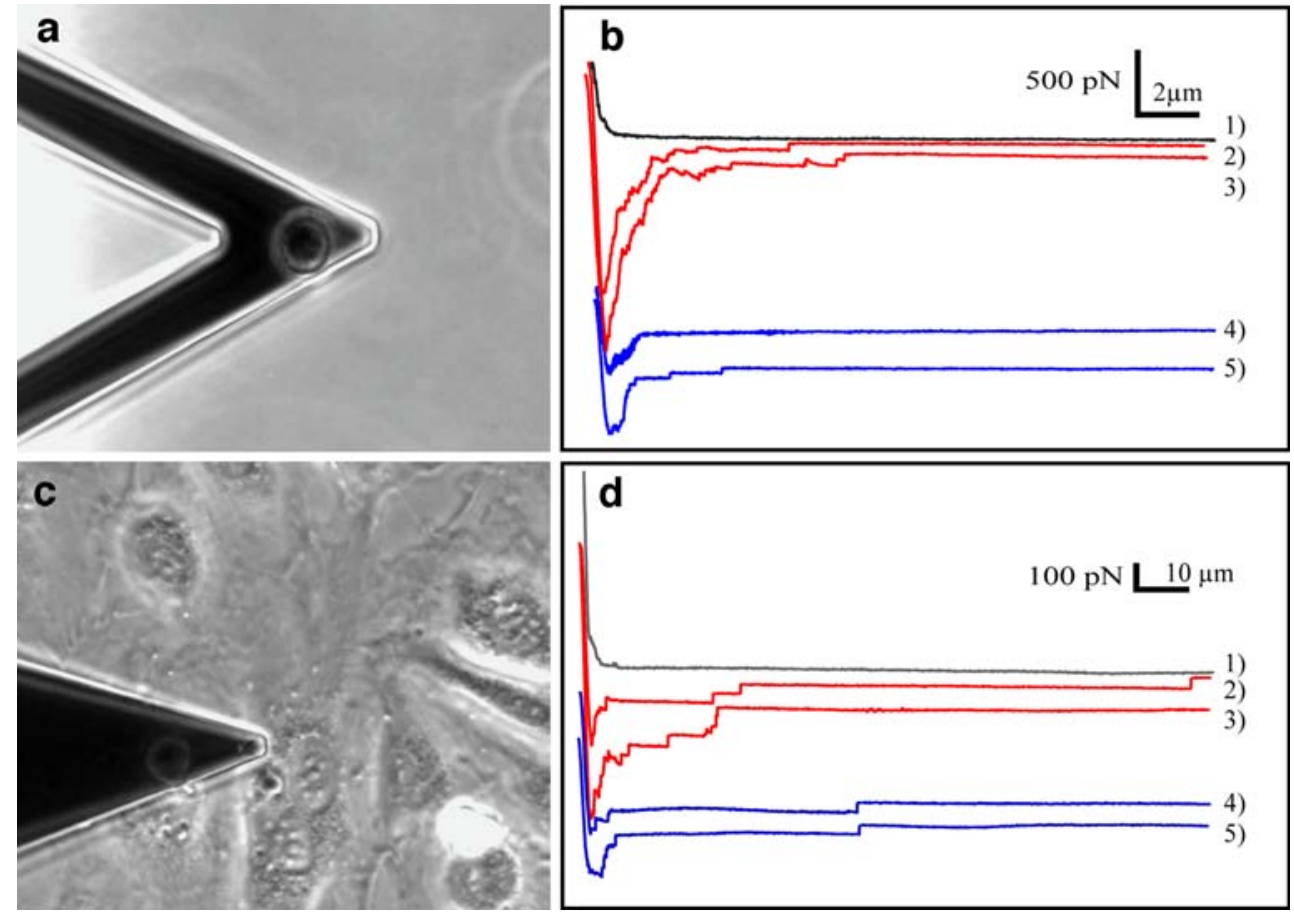

Fig. 15 Force spectroscopy of cantilever-bound cells. a Unbinding of a single melanoma (WM115) cell from a and b a fibronectin-coated detected. The maximal unbinding force was reduced after incubation with RGD peptide. b Typical force curves are displayed for different contact times. The approach speed was set to a speed of $10 \mu \mathrm{m} / \mathrm{s}(\mathbf{d}$, 1). After reaching a preset force, the contact was maintained for the 5 (d, 2 and 4) or $20 \mathrm{~s} \mathrm{(d,} 3$ and 5). Cells were separated at $10 \mu \mathrm{m} / \mathrm{s}$. Adhesion events were recorded at long cell-surface distances when calcium was present in the media (d, 2 and 3 ). Some were preceded by long force plateaus (several micrometers) that are likely to be the signature of membrane tethers. Calcium removal (d, 4 and 5) reduced the maximal unbinding force $[87,120]$

spectroscopy techniques was used to quantify leukocyte stiffness and adhesion in response to phorbol myristate acetate stimulation $[169,170]$. Single-cell force spectroscopy was used to monitor leukocyte function-associated antigen1-mediated adhesion of cells to immobilized ICAM-1, and nanoindentation by AFM was used to quantify cell elasticity. The obtained data indicated a connection between mechanical cell compliance and molecular binding events in leukocyte adhesion but also highlight the intrinsic difficulty to interpret complex force spectroscopy data towards conclusive models (Figs. 10 and 11; compare "Challenges in combining experiment and theory").

Although coordinated cell adhesion is undoubtedly critical for morphogenesis, it can prove difficult to obtain direct experimental evidence for its relevance. The arrangement of cells in three germ layers (ectoderm, endoderm, and mesoderm) during vertebrate gastrulation sets for example the stage for subsequent organogenesis [163]. This multistep event has been known to involve Wnt11 signaling, which regulates cell migration at the onset of gastrulation [32, 59].
Notwithstanding, Wnt11's immediate mode of action had been largely unclear. Single-cell force spectroscopy by AFM revealed the function of Wnt11 in cell adhesion during gastrulation in zebrafish, a popular model for vertebrate organogenesis [121]. Wnt11 was eventually proven to decrease the adhesion of mesendodermal progenitor cells to fibronectin, an abundant ECM component during gastrulation [121, 168]. Later studies employing a similar force spectroscopy setting identified this effect to be based on a novel Wnt signaling mechanism in gastrulation [160]. It was demonstrated that Wnt11 modulates E-cadherin-mediated cell adhesion through Rab5c.

\section{Perspectives}

Recent years have witnessed an exciting development in achieving unique biological insights with innovative methods from the physical sciences. In regard to AFM, this versatile tool is now being rapidly developed for biological 
applications in conjunction with other methods such as fluorescence microscopy. One of the big advantages of AFM is that it allows us to combine high-resolution imaging with direct probing of biophysical parameters. In general, the AFM's ability to simultaneously probe the topographical, chemical, adhesive, and mechanical properties of cells in a temporal and spatially resolved manner is unsurpassed. By employing complementary AFM techniques, the regulators and kinetics of different cellular processes can be addressed under physiological and transformed conditions. This renders AFM a particularly suited tool for the investigation of basic mechanisms in tissue remodeling. The power of AFM is even increased when being combined with theoretical modeling. Many molecular processes can lead to similar outcomes in AFM experiments; thus, quantitative analysis might be crucial to determine the dominant effect in a given experiment.

The quantitative study of the molecular mechanisms that promote tissue turnover, either physiological, as in normal development, or pathological, as in cancer, has led to dramatic advances in our understanding of these processes. The great challenge of the future will be to disentangle the relative importance of the different clues encountered by a cell in its microenvironment, including matrix stiffness, organization of adhesive and fiber degrees of freedom, and presence of soluble factors like growth factors, chemokines, or hormones. For example, proteases are integral constituents of a broad range of physiological and pathological processes, ranging from embryogenesis to inflammatory disorders. However, the functionally relevant parameter for all these processes is not the concentration but the spatial distribution of proteolytic activity. In this context, the use of the AFM and the quantitative analysis of the resulting data offer a unique chance for understanding these processes in more detail, eventually leading to improved drugs for biomedical applications.

\footnotetext{
Acknowledgments We thank Professor Daniel Mueller and his laboratory for their generous support, Sylvia Puttman and Volker Senner for their cooperation and contribution of primary brain tumor cells, Roland Baron and his laboratory for osteoclast cultures, Uwe Hansen for human basement membrane preparations, and Michael J. Morton for interesting discussions and reviewing this manuscript. Imaging was performed with a NanoWizard II (JPK Instruments, Berlin, Germany) and with a Nikon C1 confocal microscope. All optical images were calibrated using the DirectOverlay function of the NanoWizardII software to compensate distortions. AFM data analysis and image generation were performed with the Scanning Probe Image Processor, SPIP (Image Metrology, Lyngby, Denmark) and the software provided by JPK. The research presented here has been supported by the Deutsche Forschungsgemeinschaft (DFG grants LU854/2-1, LU854/2-2, and LU854/3-1), the Helmholtz-Gemeinschaft (DKFZ Impuls und Vernetzungsfonds 2007) and the Center for Modelling and Simulation in the Biosciences (BIOMS) at the University of Heidelberg.
}

\section{References}

1. Abiko Y, Kutsuzawa M, Kowashi Y, Kaku T, Tachikawa T (1999) In situ detection of gelatinolytic activity in developing craniofacial tissues. Anat Embryol (Berl) 200:283-287

2. Albrecht TR, Albrecht TR, Akamine S, Akamine S, Carver TE, Carver TE, Quate CF, Quate CF (1990) Microfabrication of cantilever styli for the atomic force microscope. J Vac Sci Technol A 8:3386-3396

3. Alfandari D, Cousin H, Gaultier A, Smith K, White JM, Darribere T, Desimone DW (2001) Xenopus ADAM 13 is a metalloprotease required for cranial neural crest-cell migration. Curr Biol 11:918-930

4. Arnold M, Cavalcanti-Adam EA, Glass R, Blummel J, Eck W, Kantlehner M, Kessler H, Spatz JP (2004) Activation of integrin function by nanopatterned adhesive interfaces. ChemPhysChem 5:383-388

5. Baker AH, Edwards DR, Murphy G (2002) Metalloproteinase inhibitors: biological actions and therapeutic opportunities. J Cell Sci 115:3719-3727

6. Ballestrem C, Hinz B, Imhof B, Wehrle-Haller B (2001) Marching at the front and dragging behind: differential alphaVbeta3-integrin turnover regulates focal adhesion behavior. J Cell Biol 155:1319-1332

7. Baro AM, Miranda R, Alaman J, Garcia N, Binnig G, Rohrer H, Gerber C, Carrascosa JL (1985) Determination of surface topography of biological specimens at high resolution by scanning tunnelling microscopy. Nature 315:253-254

8. Ben-Ze'ev A, Farmer SR, Penman S (1980) Protein synthesis requires cell-surface contact while nuclear events respond to cell shape in anchorage-dependent fibroblasts. Cell 21:365-372

9. Benoit M, Gabriel D, Gerisch G, Gaub HE (2000) Discrete interactions in cell adhesion measured by single-molecule force spectroscopy. Nat Cell Biol 2:313-317

10. Bershadsky AD, Balaban NQ, Geiger B (2003) Adhesiondependent cell mechanosensitivity. Annu Rev Cell Dev Biol 19:677-695

11. Binnig G, QCFGCh (1986) Atomic force microscope. Phys Rev Lett 56:930-933

12. Binnig G, RHGChWE (1982) Surface studies by scanning tunneling microscopy. Phys Rev Lett 49:57-61

13. Bischofs IB, Schwarz US (2003) Cell organization in soft media due to active mechanosensing. Proc Natl Acad Sci USA 100:9274-9279

14. Bogenrieder T, Herlyn M (2003) Axis of evil: molecular mechanisms of cancer metastasis. Oncogene 22:6524-6536

15. Brinckerhoff CE, Matrisian LM (2002) Matrix metalloproteinases: a tail of a frog that became a prince. Nat Rev Mol Cell Biol 3:207214

16. Brown PD (1995) Matrix metalloproteinase inhibitors: a novel class of anticancer agents. Adv Enzyme Regul 35:293-301

17. Brunner CA, Ehrlicher A, Kohlstrunk B, Knebel D, Kas JA, Goegler M (2006) Cell migration through small gaps. Eur Biophys J 35:713-719

18. Burridge K, Chrzanowska-Wodnicka M (1996) Focal adhesions, contractility, and signaling. Annu Rev Cell Dev Biol 12:463-518

19. Butt H-J, Jaschke M (1995) Calculation of thermal noise in atomic force microscopy. Nanotechnology 6:1-7

20. Cao J, Sato H, Takino T, Seiki M (1995) The C-terminal region of membrane type matrix metalloproteinase is a functional transmembrane domain required for pro-gelatinase A activation. J Biol Chem 270:801-805

21. Catania JM, Chen G, Parrish AR (2007) Role of matrix metalloproteinases in renal pathophysiologies. Am J Physiol Renal Physiol 292:F905-F911 
22. Chen CS, Mrksich M, Huang S, Whitesides GM, Ingber DE (1997) Geometric control of cell life and death. Science 276:1425-1428

23. Chun TH, Sabeh F, Ota I, Murphy H, McDonagh KT, Holmbeck K, Birkedal-Hansen H, Allen ED, Weiss SJ (2004) MT1-MMPdependent neovessel formation within the confines of the threedimensional extracellular matrix. J Cell Biol 167:757-767

24. Cleveland JP, Cleveland JP, Manne S, Manne S, Bocek D, Bocek D, Hansma PK, Hansma PK (1993) A nondestructive method for determining the spring constant of cantilevers for scanning force microscopy. Rev Sci Instrum 64:403-405

25. Coman DR (1944) Decreased mutual adhesiveness, a property of cells from squamous cell carcinomas. Cancer Res 4:625-629

26. Coussens LM, Fingleton B, Matrisian LM (2002) Matrix metalloproteinase inhibitors and cancer: trials and tribulations. Science 295:2387-2392

27. Crawford BD, Pilgrim DB (2005) Ontogeny and regulation of matrix metalloproteinase activity in the zebrafish embryo by in vitro and in vivo zymography. Dev Biol 286:405-414

28. Cukierman E, Pankov R, Stevens DR, Yamada KM (2001) Taking cell-matrix adhesions to the third dimension. Science 294:1708-1712

29. Cukierman E, Pankov R, Yamada KM (2002) Cell interactions with three-dimensional matrices. Curr Opin Cell Biol 14:633-639

30. Debari K, Sasaki T, Udagawa N, Rifkin BR (1995) An ultrastructural evaluation of the effects of cysteine-proteinase inhibitors on osteoclastic resorptive functions. Calcif Tissue Int 56:566-570

31. Discher DE, Janmey P, Wang YL (2005) Tissue cells feel and respond to the stiffness of their substrate. Science 310:1139-1143

32. Djiane A, Riou J, Umbhauer M, Boucaut J, Shi D (2000) Role of frizzled 7 in the regulation of convergent extension movements during gastrulation in Xenopus laevis. Development 127:3091-3100

33. Domke J, Dannohl S, Parak WJ, Muller O, Aicher WK, Radmacher M (2000) Substrate dependent differences in morphology and elasticity of living osteoblasts investigated by atomic force microscopy. Colloids Surf B Biointerfaces 19:367-379

34. Egeblad M, Werb Z (2002) New functions for the matrix metalloproteinases in cancer progression. Nat Rev Cancer 2:161-174

35. Eibl RH, Moy VT (2005) Atomic force microscopy measurements of protein-ligand interactions on living cells. Methods Mol Biol 305:439-450

36. Engel A, Gaub HE, Muller DJ (1999) Atomic force microscopy: a forceful way with single molecules. Curr Biol 9:R133-R136

37. Engler A, Bacakova L, Newman C, Hategan A, Griffin M, Discher D (2004) Substrate compliance versus ligand density in cell on gel responses. Biophys J 86:617-628

38. Engler AJ, Griffin MA, Sen S, Bonnemann CG, Sweeney HL, Discher DE (2004) Myotubes differentiate optimally on substrates with tissue-like stiffness: pathological implications for soft or stiff microenvironments. J Cell Biol 166:877-887

39. Engler AJ, Rehfeldt F, Sen S, Discher DE (2007) Microtissue elasticity: measurements by atomic force microscopy and its influence on cell differentiation. Methods Cell Biol 83:521-545

40. Engler AJ, Sen S, Sweeney HL, Discher DE (2006) Matrix elasticity directs stem cell lineage specification. Cell 126:677-689

41. Erdmann T, Schwarz US (2004) Stability of adhesion clusters under constant force. Phys Rev Lett 92:108102

42. Evans E, Ritchie K (1997) Dynamic strength of molecular adhesion bonds. Biophys J 72:1541-1555

43. Evans EA, Calderwood DA (2007) Forces and bond dynamics in cell adhesion. Science 316:1148-1153

44. Frey MT, Engler A, Discher DE, Lee J, Wang YL (2007) Microscopic methods for measuring the elasticity of gel substrates for cell culture: microspheres, microindenters, and atomic force microscopy. Methods Cell Biol 83:47-65
45. Friedrichs J, Taubenberger A, Franz CM, Muller DJ (2007) Cellular remodelling of individual collagen fibrils visualized by time-lapse AFM. J Mol Biol 372:594-607 [Copyright Elsevier]

46. Frisch SM, Francis H (1994) Disruption of epithelial cell-matrix interactions induces apoptosis. J Cell Biol 124:619-626

47. Fuchs E, Tumbar T, Guasch G (2004) Socializing with the neighbors: stem cells and their niche. Cell 116:769-778

48. Galvez BG, Matias-Roman S, Albar JP, Sanchez-Madrid F, Arroyo AG (2001) Membrane type 1-matrix metalloproteinase is activated during migration of human endothelial cells and modulates endothelial motility and matrix remodeling. J Biol Chem 276:37491-37500

49. Gang EJ, Jeong JA, Hong SH, Hwang SH, Kim SW, Yang IH, Ahn C, Han H, Kim H (2004) Skeletal myogenic differentiation of mesenchymal stem cells isolated from human umbilical cord blood. Stem Cells 22:617-624

50. Geiger B, Bershadsky A, Pankov R, Yamada KM (2001) Transmembrane crosstalk between the extracellular matrixcytoskeleton crosstalk. Nat Rev Mol Cell Biol 2:793-805

51. Georges PC, Janmey PA (2005) Cell type-specific response to growth on soft materials. J Appl Physiol 98:1547-1553

52. Gibson CT, Watson GS, Myhra S (1996) Determination of the spring constants of probes for force microscopy/spectroscopy. Nanotechnology 7:259-262

53. Gillespie PG, Walker RG (2001) Molecular basis of mechanosensory transduction. Nature 413:194-202

54. Golovko DS, Haschke T, Wiechert W, Bonaccurso E (2007) Nondestructive and noncontact method for determining the spring constant of rectangular cantilevers. Rev Sci Instrum 78:043705

55. Graham JS, Vomund AN, Phillips CL, Grandbois M (2004) Structural changes in human type I collagen fibrils investigated by force spectroscopy. Exp Cell Res 299:335-342

56. Gross J, Lapiere CM (1962) Collagenolytic activity in amphibian tissues: a tissue culture assay. Proc Natl Acad Sci USA 48:1014-1022

57. Hanahan D, Weinberg RA (2000) The hallmarks of cancer. Cell 100:57-70

58. Hassenkam T, Jorgensen HL, Lauritzen JB (2006) Mapping the imprint of bone remodeling by atomic force microscopy. Anat Rec A Discov Mol Cell Evol Biol 288:1087-1094

59. Heisenberg CP, Tada M, Rauch GJ, Saude L, Concha ML, Geisler R, Stemple DL, Smith JC, Wilson SW (2000) Silberblick/ Wnt11 mediates convergent extension movements during zebrafish gastrulation. Nature 405:76-81

60. Henderson E, Haydon PG, Sakaguchi DS (1992) Actin filament dynamics in living glial cells imaged by atomic force microscopy. Science 257:1944-1946

61. Henderson RM, Schneider S, Li Q, Hornby D, White SJ, Oberleithner H (1996) Imaging ROMK1 inwardly rectifying ATP-sensitive $\mathrm{K}+$ channel protein using atomic force microscopy. Proc Natl Acad Sci USA 93:8756-8760

62. Hernandez-Barrantes S, Bernardo M, Toth M, Fridman R (2002) Regulation of membrane type-matrix metalloproteinases. Semin Cancer Biol 12:131-138

63. Hertz HJ (1882) Über die Berührung fester elastischer Körper. J Reine Angew Math 92:156-171

64. Hinterdorfer P, Baumgartner W, Gruber HJ, Schilcher K, Schindler H (1996) Detection and localization of individual antibody-antigen recognition events by atomic force microscopy. Proc Natl Acad Sci USA 93:3477-3481

65. Hofmann UG, Rotsch C, Parak WJ, Radmacher M (1997) Investigating the cytoskeleton of chicken cardiocytes with the atomic force microscope. J Struct Biol 119:84-91

66. Holmbeck K, Bianco P, Caterina J, Yamada S, Kromer M, Kuznetsov SA, Mankani M, Robey PG, Poole AR, Pidoux I, Ward JM, Birkedal-Hansen H (1999) MT1-MMP-deficient mice 
develop dwarfism, osteopenia, arthritis, and connective tissue disease due to inadequate collagen turnover. Cell 99:81-92

67. Holmbeck K, Bianco P, Yamada S, Birkedal-Hansen H (2004) MT1-MMP: a tethered collagenase. J Cell Physiol 200:11-19

68. Hotary K, Allen E, Punturieri A, Yana I, Weiss SJ (2000) Regulation of cell invasion and morphogenesis in a threedimensional type I collagen matrix by membrane-type matrix metalloproteinases 1, 2, and 3. J Cell Biol 149:1309-1323

69. Huang S, Ingber DE (1999) The structural and mechanical complexity of cell-growth control. Nat Cell Biol 1:E131-E138

70. Huang X, Huang P, Robinson MK, Stern MJ, Jin Y (2003) UNC-71, a disintegrin and metalloprotease (ADAM) protein, regulates motor axon guidance and sex myoblast migration in C. elegans. Development 130:3147-3161

71. Hutter JL, Hutter JL, Bechhoefer J, Bechhoefer J (1993) Calibration of atomic-force microscope tips. Rev Sci Instrum 64:1868-1873

72. Ingber DE, Folkman J (1989) Mechanochemical switching between growth and differentiation during fibroblast growth factor-stimulated angiogenesis in vitro: role of extracellular matrix. J Cell Biol 109:317-330

73. Itoh Y, Seiki M (2004) MT1-MMP: an enzyme with multidimensional regulation. Trends Biochem Sci 29:285-289

74. Jiang X, Bruzewicz DA, Wong AP, Piel M, Whitesides GM (2005) Directing cell migration with asymmetric micropatterns. Proc Natl Acad Sci USA 102:975-978

75. Kandow CE, Georges PC, Janmey PA, Beningo KA (2007) Polyacrylamide hydrogels for cell mechanics: steps toward optimization and alternative uses. Methods Cell Biol 83: 29-46

76. Krammer A, Lu H, Isralewitz B, Schulten K, Vogel V (1999) Forced unfolding of the fibronectin type III module reveals a tensile molecular recognition switch. Proc Natl Acad Sci USA 96:1351-1356

77. Kusick S, Bertram H, Oberleithner H, Ludwig T (2005) Nanoscale imaging and quantification of local proteolytic activity. J Cell Physiol 204:767-774

78. Lecuit T, Lenne PF (2007) Cell surface mechanics and the control of cell shape, tissue patterns and morphogenesis. Nat Rev Mol Cell Biol 8:633-644

79. Lehnert D, Wehrle-Haller B, David C, Weiland U, Ballestrem C, Imhof BA, Bastmeyer M (2004) Cell behaviour on micropatterned substrata: limits of extracellular matrix geometry for spreading and adhesion. J Cell Sci 117:41-52

80. Lemieux GA, Blumenkron F, Yeung N, Zhou P, Williams J, Grammer AC, Petrovich R, Lipsky PE, Moss ML, Werb Z (2007) The low affinity IgE receptor (CD23) is cleaved by the metalloproteinase ADAM10. J Biol Chem 282:14836-14844

81. Lieber SC, Aubry N, Pain J, Diaz G, Kim SJ, Vatner SF (2004) Aging increases stiffness of cardiac myocytes measured by atomic force microscopy nanoindentation. Am J Physiol Heart Circ Physiol 287:H645-H651

82. Lin H, Clegg DO, Lal R (1999) Imaging real-time proteolysis of single collagen I molecules with an atomic force microscope. Biochemistry 38:9956-9963

83. Liotta LA, Tryggvason K, Garbisa S, Hart I, Foltz CM, Shafie S (1980) Metastatic potential correlates with enzymatic degradation of basement membrane collagen. Nature 284:67-68

84. Lo CM, Wang HB, Dembo M, Wang YL (2000) Cell movement is guided by the rigidity of the substrate. Biophys J 79:144-152

85. Ludwig $\mathrm{T}$ (2005) Local proteolytic activity in tumor cell invasion and metastasis. Bioessays 27:1181-1191

86. Ludwig $\mathrm{T}$ (2006) Nanotechnological approaches to cancer diagnosis: imaging and quantification of pericellular proteolytic activity. In: Kumar C (ed) Nanomaterials for cancer diagnosis. Wiley, New York, pp 377-412
87. Ludwig T, Kirmse R, Poole K (2007) Challenges and approachesprobing tumor cell invasion by Atomic Force Microscopy. In: Mendez-Vilas A, Diaz J (eds) Modern research and educational topics in microscopy no. III. vol. I. Formatex, Spain, pp 11-22

88. Ludwig T, Ossig R, Graessel S, Wilhelmi M, Oberleithner H, Schneider SW (2002) The electrical resistance breakdown assay determines the role of proteinases in tumor cell invasion. Am J Physiol Renal Physiol 283:F319-F327

89. Ludwig T, Puttmann S, Bertram H, Tatenhorst L, Paulus W, Oberleithner H, Senner V (2005) Functional measurement of local proteolytic activity in living cells of invasive and noninvasive tumors. J Cell Physiol 202:690-697

90. Maier B, Potter L, So M, Long CD, Seifert HS, Sheetz MP (2002) Single pilus motor forces exceed 100 pN. Proc Natl Acad Sci USA 99:16012-16017

91. Marshall BT, Long M, Piper JW, Yago T, McEver RP, Zhu C (2003) Direct observation of catch bonds involving cell-adhesion molecules. Nature 423:190-193

92. Marshall GW Jr, Marshall SJ, Balooch M, Kinney JH (2004) Evaluating demineralization and mechanical properties of human dentin with AFM. Methods Mol Biol 242:141-159

93. Martin P (1997) Wound healing-aiming for perfect skin regeneration. Science 276:75-81

94. Mathur AB, Truskey GA, Reichert WM (2000) Atomic force and total internal reflection fluorescence microscopy for the study of force transmission in endothelial cells. Biophys J 78:1725-1735

95. McBeath R, Pirone DM, Nelson CM, Bhadriraju K, Chen CS (2004) Cell shape, cytoskeletal tension, and RhoA regulate stem cell lineage commitment. Dev Cell 6:483-495

96. McCawley LJ, Matrisian LM (2001) Matrix metalloproteinases: they're not just for matrix anymore!. Curr Opin Cell Biol 13:534-540

97. Meredith JE Jr, Fazeli B, Schwartz MA (1993) The extracellular matrix as a cell survival factor. Mol Biol Cell 4:953-961

98. Merkel R, Nassoy P, Leung A, Ritchie K, Evans E (1999) Energy landscapes of receptor-ligand bonds explored with dynamic force spectroscopy. Nature 397:50-53

99. Moore KA, Polte T, Huang S, Shi B, Alsberg E, Sunday ME, Ingber DE (2005) Control of basement membrane remodeling and epithelial branching morphogenesis in embryonic lung by Rho and cytoskeletal tension. Dev Dyn 232:268-281

100. Mott JD, Werb Z (2004) Regulation of matrix biology by matrix metalloproteinases. Curr Opin Cell Biol 16:558-564

101. Nakahara H, Howard L, Thompson EW, Sato H, Seiki M, Yeh Y, Chen WT (1997) Transmembrane/cytoplasmic domain-mediated membrane type 1-matrix metalloprotease docking to invadopodia is required for cell invasion. Proc Natl Acad Sci USA 94: 7959-7964

102. Nelson CM, Jean RP, Tan JL, Liu WF, Sniadecki NJ, Spector AA, Chen CS (2005) Emergent patterns of growth controlled by multicellular form and mechanics. Proc Natl Acad Sci USA 102:11594-11599

103. Ng SP, Billings KS, Ohashi T, Allen MD, Best RB, Randles LG, Erickson HP, Clarke J (2007) Designing an extracellular matrix protein with enhanced mechanical stability. Proc Natl Acad Sci USA 104:9633-9637

104. Oberhauser AF, Badilla-Fernandez C, Carrion-Vazquez M, Fernandez JM (2002) The mechanical hierarchies of fibronectin observed with single-molecule AFM. J Mol Biol 319: 433-447

105. Oberhauser AF, Marszalek PE, Erickson HP, Fernandez JM (1998) The molecular elasticity of the extracellular matrix protein tenascin. Nature 393:181-185

106. Oberleithner $\mathrm{H}$ (2007) Is the vascular endothelium under the control of aldosterone? Facts and hypothesis. Pflugers Arch 454:187-193 
107. Oberleithner H, Giebisch G, Geibel J (1993) Imaging the lamellipodium of migrating epithelial cells in vivo by atomic force microscopy. Pflugers Arch 425:506-510

108. Oberleithner H, Riethmuller C, Ludwig T, Hausberg M, Schillers $\mathrm{H}$ (2006) Aldosterone remodels human endothelium. Acta Physiol (Oxf) 187:305-312

109. Oberleithner H, Riethmuller C, Ludwig T, Shahin V, Stock C, Schwab A, Hausberg M, Kusche K, Schillers H (2006) Differential action of steroid hormones on human endothelium. J Cell Sci 119:1926-1932

110. Oda T, Kanai Y, Oyama T, Yoshiura K, Shimoyama Y, Birchmeier W, Sugimura T, Hirohashi S (1994) E-cadherin gene mutations in human gastric carcinoma cell lines. Proc Natl Acad Sci USA 91:1858-1862

111. Oesterhelt F, Oesterhelt D, Pfeiffer M, Engel A, Gaub HE, Muller DJ (2000) Unfolding pathways of individual bacteriorhodopsins. Science 288:143-146

112. Oh J, Takahashi R, Adachi E, Kondo S, Kuratomi S, Noma A, Alexander DB, Motoda $\mathrm{H}$, Okada A, Seiki M, Itoh T, Itohara S, Takahashi C, Noda M (2004) Mutations in two matrix metalloproteinase genes, MMP-2 and MT1-MMP, are synthetic lethal in mice. Oncogene 23:5041-5048

113. Osenkowski P, Toth M, Fridman R (2004) Processing, shedding, and endocytosis of membrane type 1-matrix metalloproteinase (MT1-MMP). J Cell Physiol 200:2-10

114. Overall CM, Lopez-Otin C (2002) Strategies for mmp inhibition in cancer: innovations for the post-trial era. Nat Rev Cancer 2:657-672

115. Page-McCaw A, Ewald AJ, Werb Z (2007) Matrix metalloproteinases and the regulation of tissue remodelling. Nat Rev Mol Cell Biol 8:221-233

116. Parekh SH, Chaudhuri O, Theriot JA, Fletcher DA (2005) Loading history determines the velocity of actin-network growth. Nat Cell Biol 7:1219-1223

117. Pelham RJ Jr, Wang Y (1997) Cell locomotion and focal adhesions are regulated by substrate flexibility. Proc Natl Acad Sci USA 94:13661-13665

118. Poole K, Muller D (2005) Flexible, actin-based ridges colocalise with the betal integrin on the surface of melanoma cells. Br J Cancer 92:1499-1505

119. Prass M, Jacobson K, Mogilner A, Radmacher M (2006) Direct measurement of the lamellipodial protrusive force in a migrating cell. J Cell Biol 174:767-772

120. Puech PH, Poole K, Knebel D, Muller DJ (2006) A new technical approach to quantify cell-cell adhesion forces by AFM. Ultramicroscopy 106:637-644

121. Puech PH, Taubenberger A, Ulrich F, Krieg M, Muller DJ, Heisenberg CP (2005) Measuring cell adhesion forces of primary gastrulating cells from zebrafish using atomic force microscopy. J Cell Sci 118:4199-4206

122. Radmacher M (2007) Studying the mechanics of cellular processes by atomic force microscopy. Methods Cell Biol $83: 347-372$

123. Reiss K, Ludwig A, Saftig P (2006) Breaking up the tie: disintegrin-like metalloproteinases as regulators of cell migration in inflammation and invasion. Pharmacol Ther 111:985-1006

124. Reiss K, Maretzky T, Ludwig A, Tousseyn T, de SB, Hartmann D, Saftig P (2005) ADAM10 cleavage of N-cadherin and regulation of cell-cell adhesion and beta-catenin nuclear signalling. EMBO J 24:742-752

125. Ricci D, Braga PC (2004) How the atomic force microscope works. Methods Mol Biol 242:3-12

126. Ricci D, Braga PC (2004) Imaging methods in atomic force microscopy. Methods Mol Biol 242:13-23

127. Rief M, Gautel M, Oesterhelt F, Fernandez JM, Gaub HE (1997) Reversible unfolding of individual titin immunoglobulin domains by AFM. Science 276:1109-1112
128. Rotsch C, Braet F, Wisse E, Radmacher M (1997) AFM imaging and elasticity measurements on living rat liver macrophages. Cell Biol Int 21:685-696

129. Rotsch C, Jacobson K, Radmacher M (1999) Dimensional and mechanical dynamics of active and stable edges in motile fibroblasts investigated by using atomic force microscopy. Proc Natl Acad Sci USA 96:921-926

130. Rotsch C, Radmacher M (2000) Drug-induced changes of cytoskeletal structure and mechanics in fibroblasts: an atomic force microscopy study. Biophys J 78:520-535

131. Roy P, Rajfur Z, Pomorski P, Jacobson K (2002) Microscopebased techniques to study cell adhesion and migration. Nat Cell Biol 4:E91-E96

132. Ruoslahti E, Pierschbacher MD (1987) New perspectives in cell adhesion: RGD and integrins. Science 238:491-497

133. Sagvolden G, Giaever I, Pettersen EO, Feder J (1999) Cell adhesion force microscopy. Proc Natl Acad Sci USA 96: 471-476

134. Sawada Y, Sheetz MP (2002) Force transduction by Triton cytoskeletons. J Cell Biol 156:609-615

135. Schenk S, Quaranta V (2003) Tales from the crypt[ic] sites of the extracellular matrix. Trends Cell Biol 13:366-375

136. Schnaeker EM, Ossig R, Ludwig T, Dreier R, Oberleithner H, Wilhelmi M, Schneider SW (2004) Microtubule-dependent matrix metalloproteinase-2/matrix metalloproteinase-9 exocytosis: prerequisite in human melanoma cell invasion. Cancer Res 64:8924-8931

137. Schneider SW, Larmer J, Henderson RM, Oberleithner H (1998) Molecular weights of individual proteins correlate with molecular volumes measured by atomic force microscopy. Pflugers Arch 435:362-367

138. Schneider SW, Matzke R, Radmacher M, Oberleithner H (2004) Shape and volume of living aldosterone-sensitive cells imaged with the atomic force microscope. Methods Mol Biol 242: 255-279

139. Schneider SW, Pagel P, Rotsch C, Danker T, Oberleithner H, Radmacher M, Schwab A (2000) Volume dynamics in migrating epithelial cells measured with atomic force microscopy. Pflugers Arch 439:297-303

140. Schnittler HJ, Schneider SW, Raifer H, Luo F, Dieterich P, Just I, Aktories K (2001) Role of actin filaments in endothelial cell-cell adhesion and membrane stability under fluid shear stress. Pflugers Arch 442:675-687

141. Schwarz US, Bischofs IB (2005) Physical determinants of cell organization in soft media. Med Eng Phys 27:763-772

142. Seals DF, Courtneidge SA (2003) The ADAMs family of metalloproteases: multidomain proteins with multiple functions. Genes Dev 17:7-30

143. Simon A, Durrieu MC (2006) Strategies and results of atomic force microscopy in the study of cellular adhesion. Micron 37:1-13

144. Sotomayor M, Schulten K (2007) Single-molecule experiments in vitro and in silico. Science 316:1144-1148

145. Stamenkovic I (2003) Extracellular matrix remodelling: the role of matrix metalloproteinases. J Pathol 200:448-464

146. Stark RW, Drobek T, Heckl WM (2001) Thermomechanical noise of a free $\mathrm{v}$-shaped cantilever for atomic-force microscopy. Ultramicroscopy 86:207-215

147. Sternlicht MD, Werb Z (2001) How matrix metalloproteinases regulate cell behavior. Annu Rev Cell Dev Biol 17:463-516

148. Stoker M, O’Neill C, Berryman S, Waxman V (1968) Anchorage and growth regulation in normal and virus-transformed cells. Int J Cancer 3:683-693

149. Stolz M, Raiteri R, Daniels AU, VanLandingham MR, Baschong W, Aebi U (2004) Dynamic elastic modulus of porcine articular cartilage determined at two different levels of tissue organization by indentation-type atomic force microscopy. Biophys J $86: 3269-3283$ 
150. Sun HB, Smith GN Jr, Hasty KA, Yokota H (2000) Atomic force microscopy-based detection of binding and cleavage site of matrix metalloproteinase on individual type II collagen helices. Anal Biochem 283:153-158

151. Tang MJ, Hu JJ, Lin HH, Chiu WT, Jiang ST (1998) Collagen gel overlay induces apoptosis of polarized cells in cultures: disoriented cell death. Am J Physiol 275:C921-C931

152. Taubenberger A, Cisneros DA, Friedrichs J, Puech PH, Muller DJ, Franz CM (2007) Revealing Early Steps of \{alpha\}2beta1 Integrin-mediated Adhesion to Collagen Type I by Using SingleCell Force Spectroscopy. Mol Biol Cell 18:1634-1644

153. Thery M, Jimenez-Dalmaroni A, Racine V, Bornens M, Julicher F (2007) Experimental and theoretical study of mitotic spindle orientation. Nature 447:493-496

154. Thery M, Racine V, Pepin A, Piel M, Chen Y, Sibarita JB, Bornens M (2005) The extracellular matrix guides the orientation of the cell division axis. Nat Cell Biol 7:947-953

155. Thery M, Racine V, Piel M, Pepin A, Dimitrov A, Chen Y, Sibarita JB, Bornens M (2006) Anisotropy of cell adhesive microenvironment governs cell internal organization and orientation of polarity. Proc Natl Acad Sci USA 103:19771-19776

156. Thie M, Rospel R, Dettmann W, Benoit M, Ludwig M, Gaub HE, Denker HW (1998) Interactions between trophoblast and uterine epithelium: monitoring of adhesive forces. Hum Reprod 13:3211-3219

157. Torii A, Sasaki M, Hane K, Okuma S (1996) A method for determining the spring constant of cantilevers for atomic force microscopy. Meas Sci Technol 7:179-184

158. Toth M, Osenkowski P, Hesek D, Brown S, Meroueh S, Sakr W, Mobashery S, Fridman R (2005) Cleavage at the stem region releases an active ectodomain of the membrane type 1 matrix metalloproteinase. Biochem J 387:497-506

159. Tselepis C, Chidgey M, North A, Garrod D (1998) Desmosomal adhesion inhibits invasive behavior. Proc Natl Acad Sci USA 95:8064-8069

160. Ulrich F, Concha ML, Heid PJ, Voss E, Witzel S, Roehl H, Tada M, Wilson SW, Adams RJ, Soll DR, Heisenberg CP (2003) Slb/Wnt11 controls hypoblast cell migration and morphogenesis at the onset of zebrafish gastrulation. Development 130:5375-5384

161. Uzui H, Harpf A, Liu M, Doherty TM, Shukla A, Chai NN, Tripathi PV, Jovinge S, Wilkin DJ, Asotra K, Shah PK, Rajavashisth TB (2002) Increased expression of membrane type 3-matrix metalloproteinase in human atherosclerotic plaque: role of activated macrophages and inflammatory cytokines. Circulation 106:3024-3030

162. Vestweber D (2002) Regulation of endothelial cell contacts during leukocyte extravasation. Curr Opin Cell Biol 14:587-593

163. Vleminckx K, Kemler R (1999) Cadherins and tissue formation: integrating adhesion and signaling. Bioessays 21:211-220
164. Vleminckx K, Vakaet L Jr, Mareel M, Fiers W, van RF (1991) Genetic manipulation of E-cadherin expression by epithelial tumor cells reveals an invasion suppressor role. Cell 66:107-119

165. Vogel V, Sheetz M (2006) Local force and geometry sensing regulate cell functions. Nat Rev Mol Cell Biol 7:265-275

166. Wang N, Butler JP, Ingber DE (1993) Mechanotransduction across the cell surface and through the cytoskeleton. Science 260:1124-1127

167. Watt FM, Hogan BL (2000) Out of Eden: stem cells and their niches. Science 287:1427-1430

168. Winklbauer R, Keller RE (1996) Fibronectin, mesoderm migration, and gastrulation in Xenopus. Dev Biol 177:413-426

169. Wojcikiewicz EP, Zhang X, Chen A, Moy VT (2003) Contributions of molecular binding events and cellular compliance to the modulation of leukocyte adhesion. J Cell Sci 116:2531-2539

170. Wojcikiewicz EP, Zhang X, Moy VT (2004) Force and compliance measurements on living cells using Atomic Force Microscopy (AFM). Biol Proced Online 6:1-9

171. Xu J, Rodriguez D, Petitclerc E, Kim JJ, Hangai M, Moon YS, Davis GE, Brooks PC, Yuen SM (2001) Proteolytic exposure of a cryptic site within collagen type IV is required for angiogenesis and tumor growth in vivo. J Cell Biol 154:1069-1079

172. Yeung T, Georges PC, Flanagan LA, Marg B, Ortiz M, Funaki M, Zahir N, Ming W, Weaver V, Janmey PA (2005) Effects of substrate stiffness on cell morphology, cytoskeletal structure, and adhesion. Cell Motil Cytoskelet 60:24-34

173. Zaidel-Bar R, Itzkovitz S, Ma'ayan A, Iyengar R, Geiger B (2007) Functional atlas of the integrin adhesome. Nat Cell Biol 9:858-867

174. Zaman MH, Trapani LM, Sieminski AL, Mackellar D, Gong H, Kamm RD, Wells A, Lauffenburger DA, Matsudaira P (2006) Migration of tumor cells in 3D matrices is governed by matrix stiffness along with cell-matrix adhesion and proteolysis. Proc Natl Acad Sci USA 103:10889-10894

175. Zhai Y, Hotary KB, Nan B, Bosch FX, Munoz N, Weiss SJ, Cho KR (2005) Expression of membrane type 1 matrix metalloproteinase is associated with cervical carcinoma progression and invasion. Cancer Res 65:6543-6550

176. Zhang X, Chen A, De LD, Li H, Noiri E, Moy VT, Goligorsky MS (2004) Atomic force microscopy measurement of leukocyteendothelial interaction. Am J Physiol Heart Circ Physiol 286: H359-H367

177. Zhang X, Wojcikiewicz EP, Moy VT (2006) Dynamic adhesion of T lymphocytes to endothelial cells revealed by atomic force microscopy. Exp Biol Med (Maywood) 231:1306-1312

178. Zhou HM, Weskamp G, Chesneau V, Sahin U, Vortkamp A, Horiuchi K, Chiusaroli R, Hahn R, Wilkes D, Fisher P, Baron R, Manova K, Basson CT, Hempstead B, Blobel CP (2004) Essential role for ADAM19 in cardiovascular morphogenesis. Mol Cell Biol 24:96-104 